Article

\title{
A DFT Study on the Redox Active Behavior of Carbene and Pyridine Ligands in the Oxidative and Reductive Quenching Cycles of Ruthenium Photoredox Catalysts
}

\author{
Edinson Medina and Balazs Pinter *(i) \\ Department of Chemistry, Universidad Técnica Federico Santa María, Av. España 1680, Valparaíso 2390123, Chile \\ * Correspondence: balazs.pinter@usm.cl; Tel.: +56-3226-54-230
}

Received: 6 December 2019; Accepted: 27 December 2019; Published: 6 January 2020

\begin{abstract}
In this study, a detailed look at the electronic structure changes induced by photon absorption and of the succeeding redox events of the oxidative and reductive quenching cycles of ruthenium-carbene and ruthenium-pyridine photoredox catalysts is provided through an arsenal of density functional theory-based techniques including electron density difference $\Delta \rho(\mathrm{r})$ maps, spin-density distributions, and the non-covalent interaction analysis. We introduced an efficient computational protocol to obtain accurate equilibrium structures and ground-state reduction potentials for these types of complexes, substantiated via a direct comparison to empirical X-ray structures and cyclic voltammetry measurements, respectively. Moreover, we demonstrated the utility of a hitherto unexplored approach to compute excited-state redox potentials based on the Gibbs free energy of the triplet metal-to-ligand charge transfer state ( $\left.{ }^{3} \mathrm{MLCT}\right)$. The analyzed $\Delta \rho(\mathrm{r})$ maps revealed the characteristic features of, for example, metal- and ligand-centered reductions and oxidations in both ground and excited states and MLCT processes, disclosing the active participation of carbene ligands in the redox events of homoleptic systems. Beyond analyzing ligand-ligand non-covalent interactions and redox-active behaviors of carbene and pyridine ligands side by side, the effect of such groups on the kinetics of ${ }^{3} \mathrm{MLCT}$ to ${ }^{3} \mathrm{MC}$ transition was scrutinized.
\end{abstract}

Keywords: density functional theory; N-heterocyclic carbene; ruthenium complexes; photoredox catalysis; ligand redox activity

\section{Introduction}

The development of advanced solutions and materials that enable the sustainable and eco-friendly use of resources in technologically key chemical and/or energy transformations has a high priority in the field of modern chemical science. Owing to the recent intensive efforts to design such solutions, visible-light photoredox catalysts based on transition metal complexes have emerged as promising materials. These species could facilitate valuable energy-demanding organic processes by transforming the energy of sunlight into chemical energy [1]. Amongst the most studied and best performing transition metal photoredox catalysts (TMPRCs) are the ruthenium-polypyridine and iridium-phenylpyridine (ppy) derivatives, for example, $\left[\mathrm{Ru}(\mathrm{bpy})_{3}\right]^{2+}$ (Figure 1a) and $\operatorname{Ir}(\mathrm{ppy})_{3}$, respectively [2-4]. In attempts to leverage the abundant and freely available solar energy, new developments in the design and application of these classical TMPRCs have come to light, for example, the so-called cooperative catalysis, where a photoredox catalytic system is used in synergy with another TM catalyst to facilitate chemical transformations [5-7]. Other widespread applications of the parent TMPRC platforms and other closely related iridium and ruthenium derivatives include photovoltaic-like dye-sensitized solar cells (DSSCs) [8,9], chemical sensing [10,11], photodynamic therapy [12,13], etc. 
All these applications arise from the capability of these transition metal complexes to undertake light-driven charge separation through metal-to-ligand charge transfer (MLCT) processes [14,15].

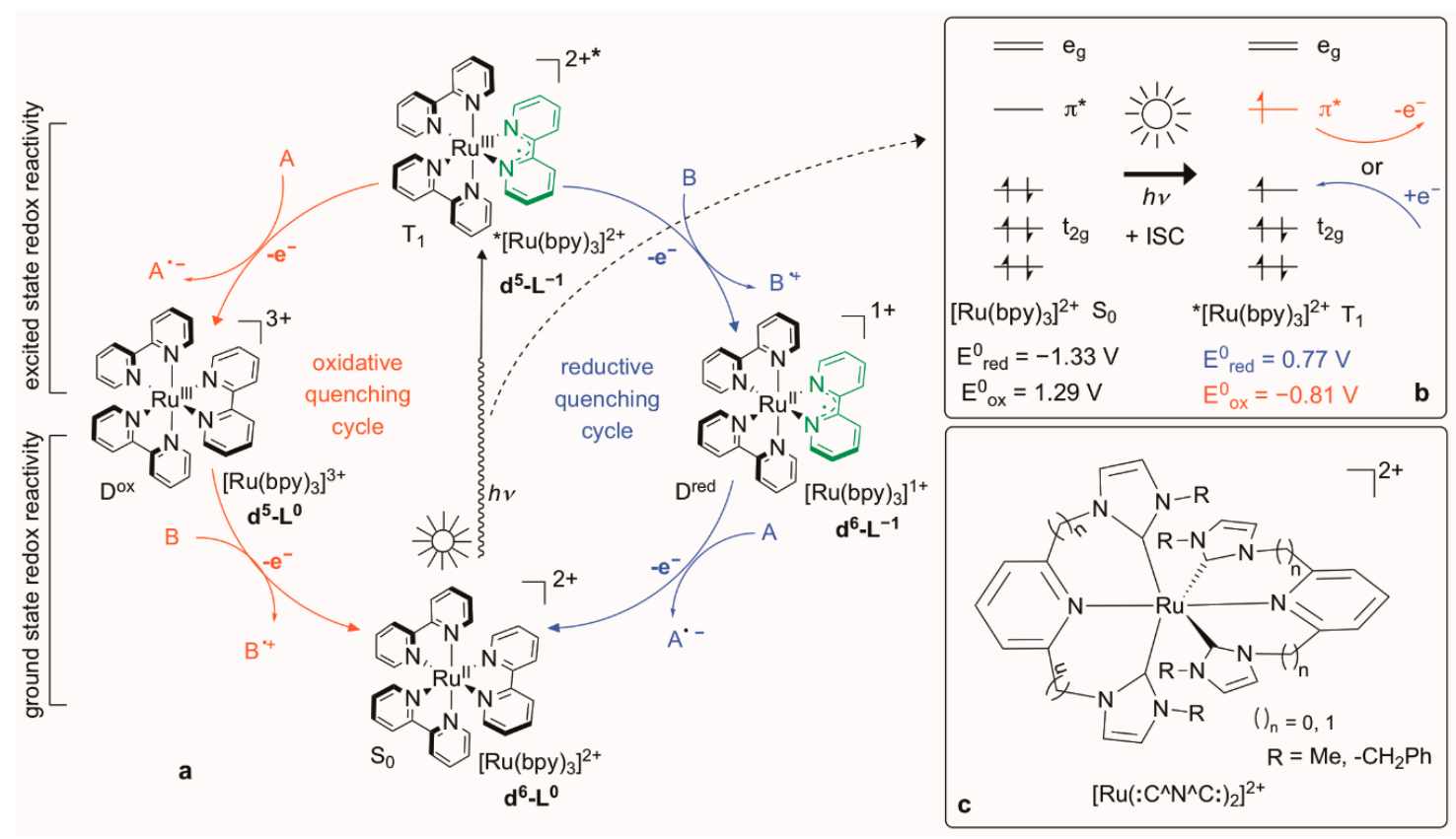

Figure 1. (a) Oxidative (red) and reductive (blue) quenching cycle of classical photoredox catalysts and formal metal-ligand oxidation state assignments for $\mathrm{S}_{0}, \mathrm{~T}_{1}, \mathrm{D}^{\text {ox }}$, and $\mathrm{D}^{\text {red }}$ states; redox potentials are given for the archetype $\left[\mathrm{Ru}(\mathrm{bpy})_{3}\right]^{2+}$ system to the saturated calomel electrode (SCE) (b) Schematic molecular orbital representation of the electronic structure changes upon photo-excitation and (c) carbene-based photoredox catalyst $\left[\mathrm{Ru}\left(: \mathrm{C}^{\wedge} \mathrm{N}^{\wedge} \mathrm{C}:\right)_{2}\right]^{2+}$ developed by Jalón and co-workers [16] for use in cooperative catalysis.

The basic photophysics of classical TMPRCs is well established and summarized in Figure 1a for the archetypal $\left[\mathrm{Ru}(\mathrm{bpy})_{3}\right]^{2+}$ (bpy $=$ bipyridine) system $[3,15,17,18]$. These ruthenium(II) and iridium(III) complexes are $\mathrm{d}^{6}$ species in their resting oxidation state forming thermodynamically stable, inert singlet ground state $\left(\mathrm{S}_{0}\right)$ octahedral complexes, where the six d electrons fill up the non-bonding $t_{2 g}$ set $[19,20]$. Absorption of a photon in the visible or near UV region promotes one of these metal-centered valence $\mathrm{d}\left(\mathrm{t}_{2 \mathrm{~g}}\right)$ electrons to a low-lying ligand-centered vacant $\pi^{*}$ orbital through a spin-allowed singlet-singlet transition [18]. This charge transfer excitation from the ground $S_{0}$ to the $S_{1}$ or $S_{2}$ excited state eventuates in a low-energy hole located at the metal and a high-energy electron mostly centered at the ligand(s). This singlet state is short lived, as it undergoes a rapid intersystem crossing (ISC) giving rise to the stable triplet ${ }^{3}$ MLCT state with an electronic structure very similar to that of the charge separated singlet state [18]. This triplet ${ }^{3}$ MLCT is typically long-lived with a lifetime of hundreds of ns or even microseconds [21], although it depends strongly on the nature of its ligands and whether the system is hetero- or homoleptic, solvent, etc. [18]. This prolonged lifetime is the key feature of photoredox catalysts that facilitates the interaction of the excited state species with external substrates through intermolecular outer-sphere single-electron transfer processes [22]. Due to the bivalent nature of the triplet ${ }^{3}$ MLCT state, the photoexcited complex is a strong reducing agent as well as a strong oxidizing agent at the same time which can manifest in either type of reactivity depending on the nature of the external substrate. The difference between the ground- and excited-state redox properties of these systems is actually striking; for example, $\left[\mathrm{Ru}(\mathrm{bpy})_{3}\right]^{2+}$ has a ground state reduction potential of $-1.33 \mathrm{~V}$ (versus SCE) for the $\left[\mathrm{Ru}(\mathrm{bpy})_{3}\right]^{2+}$ to $\left[\mathrm{Ru}(\mathrm{bpy})_{3}\right]^{1+}$ transition; however, upon absorbing light at a $\lambda_{\max }$ of $452 \mathrm{~nm}$, the reduction potential of the corresponding excited state ${ }^{*}\left[\mathrm{Ru}(\mathrm{bpy})_{3}\right]^{2+}$ to $\left[\mathrm{Ru}(\mathrm{bpy})_{3}\right]^{1+}$ process becomes $0.77 \mathrm{~V}$ (Figure $1 \mathrm{~b}$ ) [21]. According to the outlined overall mechanism, 
photoredox catalysts harvest solar energy which is transformed into a metal-centered low-energy hole and a ligand-centered high-energy electron that can be transferred to external substrates through outer-sphere electron transfer, i.e., to drive energy-demanding reactions [23-25].

As summarized in Figure 1a, the onset intermolecular interaction of the ${ }^{3}$ MLCT state determines whether the reductive quenching process or the oxidative quenching is initiated. If an electron donor transfers an electron $\left(\mathrm{B}^{+}+\mathrm{e}^{-}\right)$to the excited ${ }^{*}\left[\mathrm{Ru}(\mathrm{bpy})_{3}\right]^{2+}$ species, the reduced $\left[\mathrm{Ru}(\mathrm{bpy})_{3}\right]^{+}$, the $\mathrm{D}^{\text {red }}$ state in general, is formed which is best characterized as a ruthenium(II) species with a formally mono-reduced ligand $\left(\mathrm{L}^{-1}\right)$. In the latter oxidation state, $\left[\mathrm{Ru}(\mathrm{bpy})_{3}\right]^{+}$, the system is a strong reducing agent that transfers its ligand-centered electron to any acceptor $\left(\mathrm{A}+\mathrm{e}^{--}\right)$at a potential of $-1.33 \mathrm{~V}$ in route to the resting ground state of the system, $\left[\mathrm{Ru}(\mathrm{bpy})_{3}\right]^{2+}[18]$. The oxidative quenching cycle, on the other hand, is initiated when an electron is transferred from the ${ }^{3}$ MLCT state to an acceptor $\left(\mathrm{A}+\mathrm{e}^{--}\right)$forming $\left[\mathrm{Ru}(\mathrm{bpy})_{3}\right]^{3+}$, the $\mathrm{D}^{\mathrm{ox}}$ state in general, which is a powerful oxidant $\left(\mathrm{E}^{0}=1.29 \mathrm{~V}\right)$ while converting to the resting $\left[\mathrm{Ru}(\mathrm{bpy})_{3}\right]^{2+}$ state [18]. To close the quenching cycles as well as to utilize any of these redox steps in a catalytic fashion, sacrificial reducing or oxidizing agents need to be used as electron sources (B) or sinks (A), respectively. Tertiary amines are the most common class of reductive quenchers, whereas typical oxidizing agents include viologens, polyhalomethanes, dinitroand dicyanobenzenes and aryldiazonium salts [26-28].

Grasping the essence of the mechanism of these systems one can intuitively conclude that the unique feature of photoredox catalysis is not the ability to facilitate any specific reaction but rather its capability to turn inactive substrates into reactive radical intermediates through high-energy intermolecular outer-sphere electron transfer. Consequently, the most typical application of TMPRCs includes the generation of, among many others, electrophilic $\alpha$-carbonyl radicals [29], trifluoromethyl radicals [30], arene radical cations, iminium ions, and enone radical anions [31], of which these intermediates have been used to drive other types of transformations including atom transfer radical additions [32], arene $\mathrm{C}-\mathrm{H}$ functionalizations [25,33,34], and amine $\alpha$-functionalizations to [2 +2 ] cycloadditions $[35,36]$. Cooperative catalysis, in which another transition metal co-catalyst is sensitized through electron transfer and its catalytic cycle is supported by the photoredox catalyst has been recently added to the arsenal of applications [37-40]. The latter tandem approach holds great promise in opening new horizons for the application of photoredox catalysts using sunlight as an energy source in already established catalytic transformations.

Tailoring the redox energetics of the quenching cycles is crucial for the targeted and efficient use of photoredox catalysis. Pioneering experimental studies have revealed the direct dependence of reduction potentials in the various ground and excited state steps on metal, the ligand framework, and substitution patterns [41-43]. For example, functionalization of a given ligand frame with electron-withdrawing and/or electron-donating groups results in a significant variation of approximately $1.5 \mathrm{~V}$ in the reduction potential of ligand-centered redox events, independently of the nature of the central metal [44]. Concomitant to experimental investigations, computational studies are also playing an important role in the understanding, design, and fine-tuning of photoredox catalysts $[45,46]$. In a recent landmark study, Demissie, Ruud, and Hansen [47] established a computational approach based on ground-state and time-dependent density functional theory (DFT and TD-DFT, respectively) and implicit solvation for computing ground- and excited-state redox potentials of ruthenium and iridium complexes with the goal to advance the development of systems with improved redox properties to be used in electron transfer reactions of organic or organometallic chemistry.

Carbenes are considered amongst the most potential candidates for new ligand platforms or building blocks in photoredox catalysis, especially to effectively modulate the redox energetics and to increase the lifetime of the ${ }^{3} \mathrm{MLCT}$ state [48-50]. The unique reactivity and advantageous electronic features of heterocyclic carbenes, which can be controlled to a large extent through wingtip groups, constituting heteroatoms and backbone functionalization as outlined in Figure 2a, have already been utilized in many fields of chemistry as evidenced by the increased number of publications on the applications of carbenes in the last two decades [50,51]. Beyond the valuable intrinsic properties, another 
key feature of heterocyclic carbenes is their superior capacity to bind practically to any metal including $\mathrm{W}$ [52], Pd [53], Ir [54], Ru [55-57], Au [58], Co, Ni, and Cu [59], Fe [60,61], etc., in low-, medium-, and high-oxidation states to generate stable transition metal-carbene complexes. In spite of the handful articles on the synthesis and photo- and electrochemical characterization of carbene-containing ruthenium(II) complexes, which are indeed potential candidates for photoredox catalysis, nevertheless, to the best of our knowledge, only the very recent study by Torres et al. [16] demonstrated applied photoredox chemistry with Ru-carbene systems. Namely, complex $\left[\mathrm{Ru}\left(: \mathrm{C}^{\wedge} \mathrm{N}^{\wedge} \mathrm{C}:\right)_{2}\right]^{2+}$ (Figure 1c) and its derivatives with two tridentate ligands, each containing two substituted Arduengo carbene groups (NHC (N-heterocyclic carbene) in Figure $2 b$ ), worked effectively as photosensitizers via the corresponding oxidative quenching cycle for the $\left[\mathrm{Co}(\mathrm{bpy})_{3}\right] \mathrm{Cl}_{2}$ co-catalyst for the generation of $\mathrm{H}_{2}$ from water. These ruthenium-carbene complexes were found to have long lifetimes of approximately 1.5-1.7 $\mu \mathrm{s}$ and to have an exceptional reducing power in the excited state through the ligand-centered oxidation. Actually, the ${ }^{3}$ MLCT state of the photoredox catalyst is not quenched by the triethanolamine sacrificial reductant but by the cobalt catalyst in these tandem systems. This behavior was devoted to the high reducing power of the triplet-excited state of these $\mathrm{Ru}$-carbene complexes.

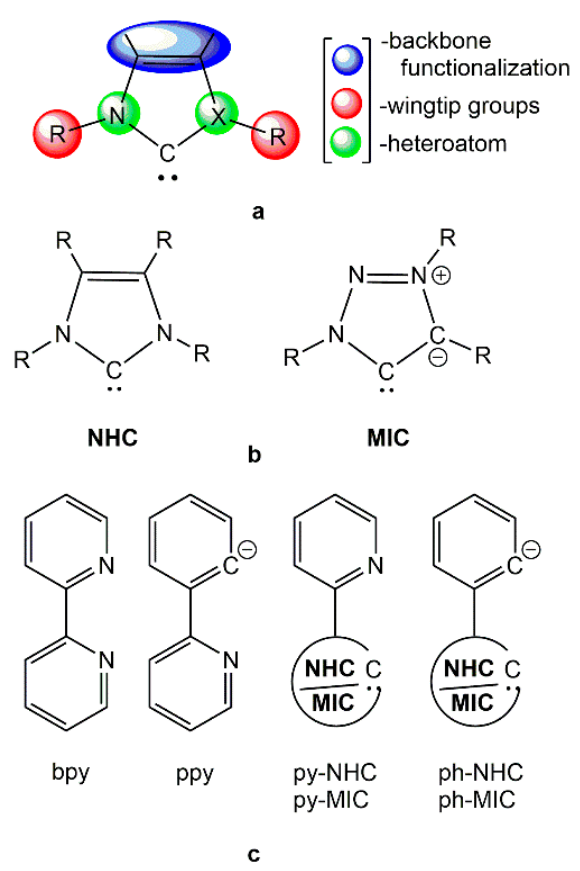

Figure 2. (a) Structural modifications to control the electronic/steric properties of carbenes; (b) general structure of N-heterocyclic carbene NHC and mesoionic carbene MIC groups used in Ru-photoredox systems; and (c) typical bidentate ligand frames based on pyridine, phenyl, and carbenes.

Mostly, two types of N-heterocyclic carbenes, Arduengo's imidazole-based carbene (NHC, Figure 2b) and the mesoionic triazolylidene ring (MIC (mesoionic carbene), Figure 2b), have so far been integrated into bi- or tridentate ligand scaffolds in the quest for a new generation of ruthenium photoredox catalysts. For the definitions of these sub-groups and for the multidimensional classifications of carbenes in general, we direct the reader's attention to the recent reviews cited herein $[48,50]$. In analogy to the bipyridine (bpy, neutral)/2-phenylpyridine (ppy, mono-anion) pair of ligands (Figure 2c) which dominate the field of classical ruthenium and iridium photoredox catalysis, the majority of the studied bidentate carbene ligands can be grouped into the pyridine-carbene (py-NHC and py-MIC, neutral) and phenyl-carbene (ph-NHC and ph-MIC, mono-anion) platforms displayed in Figure 2c. The MIC group is tethered to the phenyl or pyridine ring in these ligands either through its carbon or nitrogen adjacent to the carbene center. Benzo-fused NHC derivatives and substitutions at the carbene/pyridine/phenyl fragment at various positions represent the main 
dimensions of the chemical space for these ligands which were explored experimentally primarily within the heteroleptic $\left[\mathrm{Ru}(\mathrm{bpy})_{2} \mathrm{~L}\right]^{\mathrm{+Z}}$ ( $\mathrm{L}$ is bidentate carbene-containing ligand) complex framework (e.g., Figure 3b). Nevertheless, a few examples of the homoleptic derivatives have also been reported together with their photophysical and electrochemical characterization [16,62]. The main driving concepts of using carbene-based fragments are (i) to strengthen the metal-ligand interactions in order to destabilize the ${ }^{3} \mathrm{MC}$ state with respect to the ${ }^{3} \mathrm{MLCT}$ and ground states with which the excited state lifetime potentially increases and (ii) to manipulate the metal- and ligand-centered redox energetics (e.g., through strong $\sigma$-donation) which increases the electron density at the metal center. These concepts were put into practice, for example, by Schubert and coworkers [55] in promising ruthenium(II) photosensitizers containing two tridentate cyclometalated mesoionic carbene ligands derived from a 1,2,3-triazole scaffold and by Soellner et al. [57] and Schleicher and coworkers [56] who demonstrated, amongst others, the superior electron-donating nature of cyclometalated-carbene ligands (ph-NHC and $\mathrm{ph}-\mathrm{MIC}$ ) over the pyridine-MIC combinations in heteroleptic bipyridine ruthenium(II) complexes.

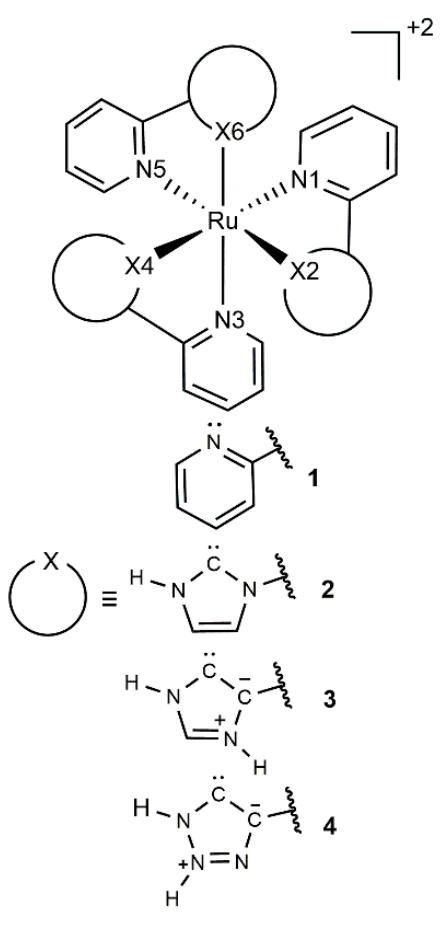

a
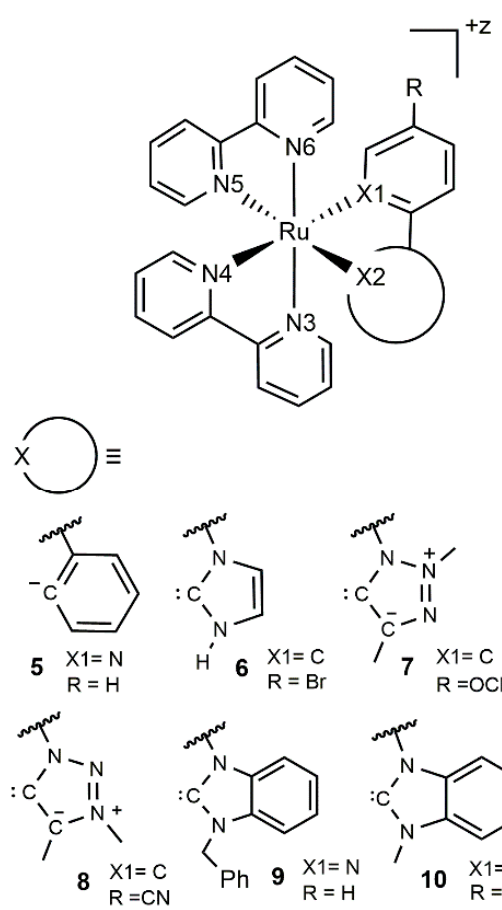

$8 \begin{aligned} & X 1=C \\ & R=C N\end{aligned}$

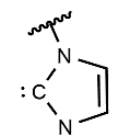

$\begin{array}{ll}H^{\prime} & 6 \begin{array}{l}\mathrm{X} 1=\mathrm{C} \\ \mathrm{R}=\mathrm{Br}\end{array}\end{array}$
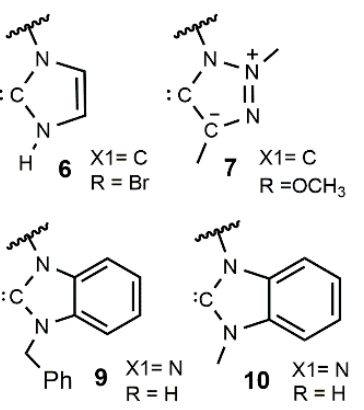

b

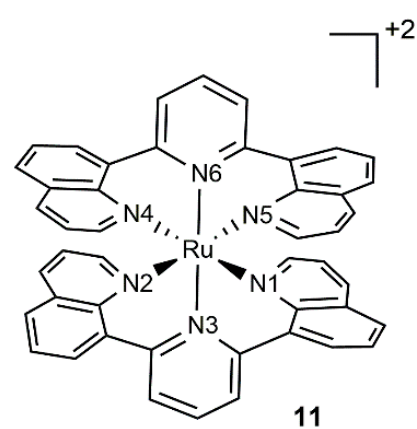

11

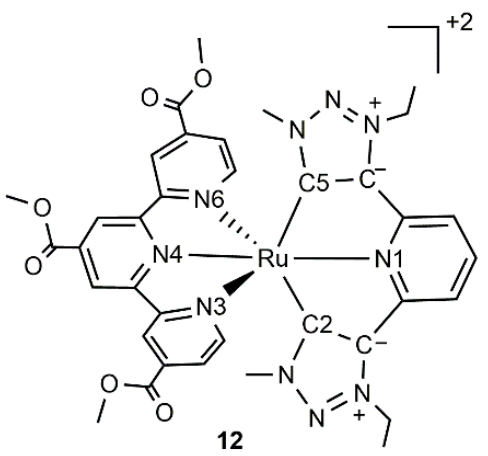

c

Figure 3. Homoleptic (a and 11) and heteroleptic (b and 12) pyridine- and carbene-ruthenium complexes based on bidentate ( $\mathbf{a}$ and $\mathbf{b}$ ) and tridentate (c) ligands investigated in this study; $\mathbf{1}$ : $\left[\mathrm{Ru}(\mathrm{bpy})_{3}\right]^{2+}, 2:\left[\mathrm{Ru}(\mathrm{py}-\mathrm{NHC})_{3}\right]^{2+}, 3:\left[\mathrm{Ru}(\mathrm{py}-a \mathrm{NHC})_{3}\right]^{2+}, 4:\left[\mathrm{Ru}(\text { py-MIC })_{3}\right]^{2+}, 5:\left[\mathrm{Ru}(\mathrm{bpy})_{2}(\mathrm{ppy})\right]^{1+}$, 6: $\left[\mathrm{Ru}(\mathrm{bpy})_{2}\left(\mathrm{ph}^{\mathrm{Br}}-\mathrm{NHC}\right)\right]^{1+}, \quad 7: \quad\left[\mathrm{Ru}(\mathrm{bpy})_{2}\left(\mathrm{ph}^{\mathrm{OMe}}-\mathrm{MIC}^{\mathrm{Me}}\right)\right]^{1+}, \quad 8: \quad\left[\mathrm{Ru}(\mathrm{bpy})_{2}\left(\mathrm{ph}^{\mathrm{CN}}-\mathrm{MIC}^{\mathrm{Me}}\right]^{1+}\right.$ 9: $\left[\mathrm{Ru}(\mathrm{bpy})_{2}\left(\mathrm{py}-f \mathrm{NHC}^{\mathrm{CH} 2 \mathrm{Ph}}\right)\right]^{2+}, \quad$ 10: $\left[\mathrm{Ru}(\mathrm{bpy})_{2}\left(\mathrm{py}-f \mathrm{NHC}^{\mathrm{Me}}\right)\right]^{2+}, \mathbf{1 1}:\left[\mathrm{Ru}(\mathrm{dqp})_{2}\right]^{2+} \mathbf{1}$ and 2: $\left[\mathrm{Ru}(\text { tpy })\left(\mathrm{C}^{\wedge} \mathrm{N}^{\wedge} \mathrm{C}\right)\right]^{2+}$.

\section{Results and Discussion}

Twelve structurally related octahedral ruthenium photoredox catalysts, shown in Figure 3, have been systematically investigated in this computational study. The three distinct groups investigated included four homoleptic pyridine/carbene complexes with bpy, py-NHC, py- $a$ NHC (prefix $a$ denotes "abnormal" [63]), and py-MIC ligands (Figure 3a); six heteroleptic systems with two bpy and one carbene-containing ligand (Figure 3b); and two of the investigated systems, 11 and 12, displayed tridentate polypyridine/carbene ligands bound in facial and meridional fashions, respectively. To analyze the electronic structure changes and redox energetics along the photoredox quenching cycles 
of these systems, presented above universally for $\left[\mathrm{Ru}(\mathrm{bpy})_{3}\right]^{2+}$ through Figure 1 , we computed the four stationary points determining the cycles, including the ground state species, $\mathrm{S}_{0}$, the triplet ${ }^{3} \mathrm{MLCT}$ state, $\mathrm{T}_{1}$, the reduced (doublet) state, $\mathrm{D}^{\text {red }}$, and the oxidized (doublet) state, $\mathrm{D}^{\mathrm{ox}}$, of all the complexes displayed in Figure 3. To ensure consistency along and easy navigation within the various species with different overall charge, spin state, etc., we systematically used the formal oxidation state assignments of the different states throughout the manuscript. Namely, the $\mathrm{S}_{0}$ ground state can be best described with a formal $\mathrm{d}^{6}-\mathrm{L}^{0}$ electron configuration (the metal has six $\mathrm{d}$ electrons, $\mathrm{Ru}^{\mathrm{II}}$, whereas the ligands are in their most stable oxidation state), the ${ }^{3} \mathrm{MLCT}$ state is formally $\mathrm{d}^{5}-\mathrm{L}^{-1}$, whereas the oxidized and reduced states, both being doublet owing to the unpaired electron, are formally $\mathrm{d}^{5}-\mathrm{L}^{0}$ the $\mathrm{d}^{6}-\mathrm{L}^{-1}$, respectively. In addition to scrutinizing the wavefunction of these states and their changes upon reduction/oxidation via DFT calculations, we computed the solution-state Gibbs free energies, $\mathrm{G}^{\text {sol }}$, of these states allowing the evaluation of the excited- and ground-state reduction potentials, which were compared to the available experimental values and discussed in the context of the chemical nature of the ligands.

In the presence of solid-state structures and experimental redox potentials for several of the studied photoredox catalysts, the computational protocol established for equilibrium structures and for solution-state Gibbs free energies can be directly substantiated. In accordance with the findings of recent DFT reports [47], our optimization procedure was based on the PBE functional coupled to a triple- $\zeta$ basis set with relativistic core potential for $\mathrm{Ru}$ allowing the simulation of the equilibrium structures of ruthenium photoredox catalysts with high accuracy at a relatively low computational cost. Other factors, especially grid quality and dispersion correction, also contribute, to a non-negligible extent, to the accuracy of the computed geometries, whereas, according to our experience with the investigated systems, the resolution-of-identity approximation significantly reduces the computational cost without inducing a notable error in the structural metrics. All these details of our computational method are detailed in the methodology section. In Table 1, structural metrics that characterize the first coordination sphere and overall geometry are collected for a representative set of systems in their corresponding singlet ground state, $\mathrm{S}_{0}$. Besides the computed bond distances and angles defined in Figure 3, the benchmark values for these structural parameters extracted from available empirical XRD structures are also reported in brackets in Table 1 . The numbering of contact atoms is shown in Figure 3.

An excellent overall agreement existed between the experimental and computed metal-ligand bond lengths for all three types of complexes investigated independently from the nature of the ligand or its binding mode to the metal. Calculated ruthenium-nitrogen distances varied between $2.03 \AA$ (in 5) and $2.14 \AA$ (in 5) and were typically within $0.01 \AA$ to measured values, when direct comparison was possible. The latter deviation was also characteristic for both types of ruthenium-carbon interactions, namely, Ru-carbene and Ru-phenyl, with the exception of the Ru- $\mathrm{C}_{\text {carbene }}$ bond of $\left[\mathrm{Ru}(\mathrm{bpy})_{2}(\mathrm{ppy})\right]^{1+}$ (5), for which the largest divergence from the X-ray metric (approximately $0.03 \AA$ ) was documented. Also, the overall arrangement around the metal characterized by the selected intra-ligand $(\mathrm{X} 1-\mathrm{Ru}-\mathrm{X} 2)$ and inter-ligand (N3-Ru-X4 and N3-Ru-X6) were modeled realistically given the excellent agreement (typically within $1^{\circ}$ ) between the experimental and computed angles, independently from the nature of the contact atom, charge of the ligand, the overall charge of the complex, and whether the system was heteroleptic or homoleptic. Only in three cases, $\left[\mathrm{Ru}(\mathrm{bpy})_{2}(\mathrm{ppy})\right]^{1+}(5)$, and $\left[\mathrm{Ru}(\mathrm{bpy})_{2}\left(\mathrm{ph}^{\mathrm{Br}}-\mathrm{NHC}\right)\right]^{1+}$ (6), and $\left[\mathrm{Ru}(\mathrm{bpy})_{2}\left(\mathrm{py}-\mathrm{fNHC} \mathrm{Ne}^{\mathrm{Me}}\right)\right]^{1+}(\mathbf{1 0})$, did one of the investigated angles deviate approximately $3^{\circ}$ from the XRD which can be still considered realistic given that the packing effects and counter ions present in the crystal can interfere with the structure of the complex to such an extent to induce such a distortion. This overall and general agreement between the experimental and computed structural parameters implies that the equilibrium structures of the investigated photoredox catalysts were simulated truthfully, substantiating the method of calculation for molecular geometries and the subsequent analysis of structural metrics. 
Table 1. Calculated and X-ray (in brackets) structural information of the first coordination sphere of selected photoredox catalysts in their corresponding singlet ground state. Bonds are listed in $\AA$ and angles are in ${ }^{\circ}$.

\begin{tabular}{|c|c|c|c|c|c|c|c|c|c|c|}
\hline Bond (̊̊) & & 1 & 2 & 3 & 4 & 5 & 6 & 7 & 8 & 10 \\
\hline \multirow{6}{*}{$\mathrm{Ru}-\mathrm{N} / \mathrm{C}$} & $\mathrm{X} 1$ & $\begin{array}{c}2.058 \\
(2.055)\end{array}$ & 2.162 & 2.181 & 2.186 & $\begin{array}{c}2.078 \\
(2.075)\end{array}$ & $\begin{array}{c}2.060 \\
(2.060)\end{array}$ & $\begin{array}{c}2.061 \\
(2.062)\end{array}$ & $\begin{array}{c}2.057 \\
(2.054)\end{array}$ & $\begin{array}{c}2.075 \\
(2.070)\end{array}$ \\
\hline & $\mathrm{X} 2$ & $\begin{array}{c}2.058 \\
(2.051)\end{array}$ & 1.972 & 1.983 & 1.980 & $\begin{array}{l}2.029 \\
(2.00)\end{array}$ & $\begin{array}{c}2.014 \\
(2.021)\end{array}$ & $\begin{array}{c}2.038 \\
(2.038)\end{array}$ & $\begin{array}{c}2.032 \\
(2.032)\end{array}$ & $\begin{array}{c}1.990 \\
(1.974)\end{array}$ \\
\hline & N3 & $\begin{array}{c}2.059 \\
(2.058)\end{array}$ & 2.161 & 2.182 & 2.187 & $\begin{array}{c}2.056 \\
(2.040)\end{array}$ & $\begin{array}{c}2.053 \\
(2.064)\end{array}$ & $\begin{array}{c}2.048 \\
(2.053)\end{array}$ & $\begin{array}{c}2.049 \\
(2.053)\end{array}$ & $\begin{array}{c}2.058 \\
(2.068)\end{array}$ \\
\hline & $X 4$ & $\begin{array}{c}2.058 \\
(2.056)\end{array}$ & 1.972 & 1.983 & 1.980 & $\begin{array}{c}2.034 \\
(2.056)\end{array}$ & $\begin{array}{c}2.121 \\
(2.116)\end{array}$ & $\begin{array}{c}2.112 \\
(2.106)\end{array}$ & $\begin{array}{c}2.110 \\
(2.105)\end{array}$ & $\begin{array}{c}2.059 \\
(2.066)\end{array}$ \\
\hline & N5 & $\begin{array}{c}2.058 \\
(2.051)\end{array}$ & 2.162 & 2.181 & 2.186 & $\begin{array}{c}2.137 \\
(2.139)\end{array}$ & $\begin{array}{c}2.095 \\
(2.095)\end{array}$ & $\begin{array}{c}2.087 \\
(2.095)\end{array}$ & $\begin{array}{c}2.091 \\
(2.096)\end{array}$ & $\begin{array}{c}2.124 \\
(2.119)\end{array}$ \\
\hline & $X 6$ & $\begin{array}{c}2.059 \\
(2.048)\end{array}$ & 1.972 & 1.983 & 1.980 & $\begin{array}{c}2.031 \\
(2.086)\end{array}$ & $\begin{array}{c}2.040 \\
(2.055)\end{array}$ & $\begin{array}{c}2.035 \\
(2.053)\end{array}$ & $\begin{array}{l}2.0416 \\
(2.055)\end{array}$ & $\begin{array}{c}2.065 \\
(2.061)\end{array}$ \\
\hline $\mathrm{X} 1-\mathrm{Ru}-\mathrm{X} 2$ & $\alpha$ & $\begin{array}{c}78.7 \\
(78.6)\end{array}$ & 77.1 & 77.5 & 77.6 & $\begin{array}{c}79.6 \\
(79.6)\end{array}$ & $\begin{array}{c}78.5 \\
(79.1)\end{array}$ & $\begin{array}{c}79.3 \\
(79.6)\end{array}$ & $\begin{array}{c}79.2 \\
(79.8)\end{array}$ & $\begin{array}{c}78.1 \\
(77.9)\end{array}$ \\
\hline N3-Ru-X4 & $\beta$ & $\begin{array}{c}78.7 \\
(78.4)\end{array}$ & 94.7 & 93.6 & 93.7 & $\begin{array}{c}77.4 \\
(77.8)\end{array}$ & $\begin{array}{c}95.2 \\
(98.8)\end{array}$ & $\begin{array}{c}94.7 \\
(93.3)\end{array}$ & $\begin{array}{c}95.5 \\
(95.9)\end{array}$ & $\begin{array}{c}96.9 \\
(93.6)\end{array}$ \\
\hline N3-Ru-X6 & $\gamma$ & $\begin{array}{c}173.5 \\
(172.3)\end{array}$ & 169.2 & 170.2 & 170.0 & $\begin{array}{c}174.1 \\
(171.8)\end{array}$ & $\begin{array}{c}173.3 \\
(172.3)\end{array}$ & $\begin{array}{c}174.2 \\
(174.8)\end{array}$ & $\begin{array}{c}173.4 \\
(172.4)\end{array}$ & $\begin{array}{c}172.1 \\
(172.6)\end{array}$ \\
\hline
\end{tabular}

$\mathrm{X} 1=\mathrm{N}$ (compounds 1-5 and 10), $\mathrm{X} 1=\mathrm{C}$ (compounds 6-8), $\mathrm{X} 2=\mathrm{N}$ (compound 1), $\mathrm{X} 2=\mathrm{C}$ (compounds 2-8 and 10), $\mathrm{X} 4=\mathrm{X} 6=\mathrm{N}$ (compounds 1, 5-8, and 10), $\mathrm{X} 4=\mathrm{X} 6=\mathrm{C}$ (compounds 2-4). Experimental values were taken from the following references $\mathbf{1}$ [64], 5 [65], 6 [56], 7-8 [57], and 10 [66].

Due to the superior $\sigma$-donor nature of carbon over nitrogen and its concomitant strong trans influence, the metal-nitrogen distances trans to metal-carbon interactions elongated by as much as $0.1 \AA$ with respect to trans-N-Ru-N arrangements. For example, the average $\mathrm{Ru}-\mathrm{N}$ distance changed from $2.059 \AA$ in the homoleptic $\left[\mathrm{Ru}(\mathrm{bpy})_{3}\right]^{2+}$ to $2.124 \AA$ trans to the $\mathrm{Ru}$-carbene $\left(f \mathrm{NHC} \mathrm{Ne}^{\mathrm{Me}}\right)$ interaction in 10 (prefix $f$ denotes benzo-fused carbenes). The latter Ru-C bond of $1.990 \AA$ A was also amongst the shortest metal-ligand bonds recorded in this study. In general, $\mathrm{Ru}-\mathrm{C}_{\text {carbene }}$ distances $(\mathrm{Ru}-\mathrm{X} 2$ in Table 1, compounds $\mathbf{2 - 4}, \mathbf{6 - 1 0}$, and $\mathbf{1 2}$ ) were somewhat smaller than $\mathrm{Ru}-\mathrm{C}_{\text {phenyl }}$ ones ( $\mathrm{Ru}-\mathrm{X} 1$ in Table 1 , compounds 6-8), and these $\mathrm{Ru}-\mathrm{C}$ bonds were notably shorter than typical $\mathrm{R}-\mathrm{N}_{\text {pyridine }}$ bonds. The most extreme distortions appeared in the homoleptic pyridine-NHC and pyridine-MIC complexes, 2, 3 and 4, where the $\mathrm{Ru}-\mathrm{C}_{\text {carbene }}$ distances shortened to 1.97-1.98 $\AA$, while the $\mathrm{Ru}-\mathrm{N}_{\text {pyridine }}$ bonds elongated up to $2.187 \AA$, clearly reflecting the superior electron donor property of carbene ligands. In addition, the confined tethering of the NHC/MIC and pyridine groups in these chelating ligands led to a non-negligible divergence from the ideal octahedral binding, which can be witnessed in the deviation of the inter-ligand and intra-ligand angles $(\alpha, \beta$, and $\gamma)$ from their model values of $90^{\circ}, 90^{\circ}$, and $180^{\circ}$, respectively. Another general observation that can be concluded from Table 1 is that NHC carbenes form slightly shorter bonds than MIC carbenes under similar circumstances. For example, going from 2 (NHC) to 3 and 4 (MICs) the Ru- $\mathrm{C}_{\text {carbene }}$ distances elongated by about $0.01 \AA$, whereas the difference was approximately $0.02 \AA$ in the heteroleptic (bis)bipyridine derivatives, e.g., going from 6 (NHC) to 7 ( $\mathrm{MIC}^{\mathrm{Me}}$ ) and 8 ( $\left.\mathrm{MIC}^{\mathrm{Me}}\right)(\mathrm{Ru}-\mathrm{X} 2$ distances in Table 1$)$. These results imply that the NHC carbenes were stronger $\sigma$-donors than the MIC groups in these ruthenium(II) complexes. This notion can also be witnessed in the $\mathrm{Ru}-\mathrm{N}_{\text {pyridine }}$ distances trans to the carbene ligands, being longer if it was trans to NHC than to MIC. Benzo-fused NHC carbenes ( $f$ NHCs), such as in complex $\mathbf{9}$ and 10, appeared as even superior $\sigma$-donors, resulting in $\mathrm{Ru}-\mathrm{C}_{\text {carbene }}$ bonds in the order of $1.99 \AA$ and further elongated $\mathrm{Ru}-\mathrm{N}_{\text {pyridine }}$ bonds trans to it.

Experimental ground- and excited-state reduction potentials have been reported for nine out of the twelve considered photoredox catalysts, which are listed in Table 2 in brackets, given together with 
the computed values for all species. It is apparent from the definition of absolute half-cell potential, Equation (1) (methodology section), that the solution-state Gibbs free energy change during reduction or oxidation has to be computed accurately in order to reproduce half-cell potentials and, subsequently, reduction potentials to a given reference system (SCE in this study). The general experience with the $\mathrm{PBE}$ functional is that it is not suitable for the computation of accurate relative energies when the electron number is not constant and, accordingly, one needs to use a different, preferably higher-rung DFT functional for the realistic simulation of redox events. In line with the conclusions of other studies [67], we repeatedly showed that the meta-GGA hybrid TPPSh functional with adequate dispersion correction captures the main features of the reduction and oxidation of transition metal complexes in terms of electronic structure and energy changes allowing the computation of accurate redox potentials [68,69].

Table 2. Computed ground- and excited-state reduction potentials for all investigated species in volts, referenced to the saturated calomel electrode (SCE), given together with the corresponding experimental values when available. Transitions that take place formally at the metal and at the ligand are denoted as $\mathrm{d}^{5} / \mathrm{d}^{6}$ and $\mathrm{L}^{0} / \mathrm{L}^{-1}$, respectively, whereas excited-state redox events are indicated by *.

\begin{tabular}{ccccc}
\hline \multicolumn{5}{c}{$\mathbf{E}^{\mathbf{0}} \mathbf{V}$ versus $\mathbf{S C E}$} \\
\cline { 2 - 5 } & \multicolumn{2}{c}{ Ground State } & \multicolumn{2}{c}{ Excited State } \\
\cline { 2 - 5 } $\mathbf{d}^{\mathbf{5}} / \mathbf{d}^{\mathbf{6}}$ & $\mathbf{L}^{\mathbf{0}} / \mathbf{L}^{-\mathbf{1}}$ & $-\mathbf{\mathbf { L } ^ { - 1 }}$ * & $\mathbf{d}^{\mathbf{5}} / \mathbf{d}^{\mathbf{6} *}$ \\
\hline $\mathbf{1}$ & $1.29(1.29)$ & $-1.27(-1.33)$ & $-0.73(-0.81)$ & $0.74(0.77)$ \\
$\mathbf{2}$ & 1.12 & -1.96 & -1.35 & 0.52 \\
$\mathbf{3}$ & 0.14 & -2.23 & -1.73 & -0.36 \\
$\mathbf{4}$ & 0.68 & -1.68 & -1.17 & 0.18 \\
$\mathbf{5}$ & $0.34(0.37)$ & $-1.61(-1.70)$ & $-1.23(-1.36)$ & $-0.04(0.03)$ \\
$\mathbf{6}$ & $0.34(0.42)$ & $-1.61(-1.66)$ & $-1.13(-1.17)$ & $-0.15(-0.06)$ \\
$\mathbf{7}$ & $0.21(0.34)$ & $-1.72(-1.67)$ & $-1.23(-1.21)$ & $-0.28(-0.12)$ \\
$\mathbf{8}$ & $0.37(0.44)$ & $-1.66(-1.65)$ & $-1.15(-1.16)$ & $-0.14(-0.05)$ \\
$\mathbf{9}$ & $1.29(1.30)$ & $-1.24(-1.37)$ & $-0.66(-0.70)$ & $0.71(0.63)$ \\
$\mathbf{1 0}$ & $1.26(1.28)$ & $-1.26(-1.36)$ & $-0.72(-0.75)$ & $0.71(0.66)$ \\
$\mathbf{1 1}$ & $0.94(1.09)$ & $-1.22(-1.34)$ & $-0.70(-0.68)$ & $0.42(0.43)$ \\
$\mathbf{1 2}$ & $1.21(1.11)$ & $-0.90(-1.08)$ & $-0.29(-0.60)$ & $0.60(0.64)$ \\
\hline
\end{tabular}

The success of the combination of TPSSh and SMD solvation method in modeling solution-state redox energetics can also be witnessed in the close match between the computed and measured ground-state reduction potentials in Table 2. For all three kinds of complexes and for both types of reductions (i.e., metal-centered $\left(\mathrm{d}^{5} / \mathrm{d}^{6}\right)$ and ligand-centered $\left.\left(\mathrm{L}^{0} / \mathrm{L}^{-1}\right)\right)$ investigated, the reduction potentials were computed within $0.15 \mathrm{~V}$ to the experimental values. As a matter of fact, the deviation from the measured reduction potentials was frequently less than $0.1 \mathrm{~V}$. This is an encouraging performance from DFT and implicit solvation, especially if one takes into account the chemical space covered. Both heteroleptic or homoleptic complexes were investigated with the overall charge varying from +3 (e.g., $\left[\mathrm{Ru}(\mathrm{bpy})_{3}\right]^{3+}$ in the $\mathrm{D}^{\mathrm{ox}}$ state) to 0 (e.g., $\left[\mathrm{Ru}(\mathrm{bpy})_{2} \text { (ph-NHC/MIC) }\right]^{0}$ systems $(6-8)$ in the $\mathrm{D}^{\text {red }}$ state); the chemical nature of ligands change significantly along the pyridine/phenyl/carbene series which can be bidentate or tridentate, substituted or non-substituted, etc. These findings suggest that accurate, efficient, and robust computational protocols can be established for the ground-state redox energetics of photoredox catalysts using DFT and implicit solvation.

It is worth noting that we have not followed the in silico protocol that was established recently by Demissie, Ruud, and Hansen [47] for computing the excited state redox potentials of photoredox catalysts. The latter study takes advantage of the fact that the reduction and oxidation quenching pathways are thermodynamic cycles with the energy of the absorbed photon being equal to the energy that is liberated in the two subsequent redox steps of each quenching cycle. Consequently, by computing the excitation energy, for example, by TD-DFT and using ground-state reduction potentials, 
the excited state redox potentials can be determined using the following formulas, where $\mathrm{E}_{00}$ represents vertical $\mathrm{S}_{0} \rightarrow \mathrm{S}_{1}$ excitation energy.

$$
\begin{aligned}
E_{\text {red }}^{0 *} & =E_{\text {red }}^{0}+E_{00} \\
E_{\text {ox }}^{0 *} & =E_{\text {ox }}^{0}-E_{00}
\end{aligned}
$$

The low rung B3LYP-D3 functional was found to be appropriate to reproduce the excited-state reduction potentials of classical ruthenium and iridium photoredox catalysts. In contrast to this approach, our computational protocol avoids the use of TD-DFT for excited-state reduction potentials and, instead, utilizes the definition equation of half-cell potentials, Equation (1), where the $\Delta G^{\text {sol }}$ values of excited state redox events are determined with respect to the triplet MLCT state. In other words, by directly computing the solution-state Gibbs free energy of the ${ }^{3}$ MLCT state using the same method as was established for ground-state energetics, the $\Delta \mathrm{G}^{\text {sol }}$ value of the excited-state oxidation and reduction processes can be easily determined using the $\mathrm{G}^{\text {sol }}$ values of $\mathrm{D}^{\mathrm{ox}}$ and $\mathrm{D}^{\text {red }}$, respectively. The corresponding excited-state reduction potentials are also given in Table 2 for the $\mathrm{L}^{0} / \mathrm{L}^{-1, *}$ and $\mathrm{d}^{6} / \mathrm{d}^{5, *}$ transitions revealing that this approach offers simulated values that agree reasonably well (within $0.2 \mathrm{~V}$ ) to experimental reduction potentials. Then again, this observation is generic, remaining true for both excited-state metal- and ligand-centered oxidations/reductions independently from the nature of the ligands, their binding mode, overall charge of the complex, etc. Only in one instance was there an unacceptable mismatch $(-0.31 \mathrm{~V})$ between theory and experiment; in complex 12 with a multi-functionalized terpyridine and a tridentate carbene containing $\mathrm{C}^{\wedge} \mathrm{N}^{\wedge} \mathrm{C}$ ligand, the excited-state ligand-centered oxidation was predicted to be at a notably more positive potential $(-0.29 \mathrm{~V})$ than experimentally determined $(-0.60 \mathrm{~V})$.

It is worth looking into some of the telltale chemical trends revealed by the reduction potentials collected in Table 1. Most importantly, seven of the studied systems (i.e., 1, 5, 6, 7, 8, 9, and 10) can be clearly grouped into two sub-classes with very similar redox properties. Namely, 1, 9, and $\mathbf{1 0}$ had reduction potentials of about $1.3 \mathrm{~V}$ for the $\mathrm{Ru}(\mathrm{III}) / \mathrm{Ru}$ (II) transition, $-1.25 \mathrm{~V}$ for the ground-state ligand-centered reduction, and approximately $-0.7 \mathrm{~V}$ and $0.7 \mathrm{~V}$ for the excited-state $\mathrm{L} / \mathrm{L}^{-1 *}$ and $\mathrm{Ru}(\mathrm{III}) / \mathrm{Ru}(\mathrm{II})^{*}$ events, respectively. On the other hand, 5, 6, 7, and 8 underwent metal-based $\mathrm{d}^{6} / \mathrm{d}^{5}$ oxidation at about $0.2-0.35 \mathrm{~V}$ and ligand-centered reduction at -1.6 to $-1.7 \mathrm{~V}$ in the ground state, and the excited-state reduction potentials of these complexes were also rather similar in spite of the difference of the constituting ligand frames. From a side-by-side comparison of the structures of these two groups, however, one can easily deduce that there was only one main structural feature that remained unchanged within a group but changed along the two groups which was the pyridine versus phenyl group in the carbene-containing ligands. Namely, all these complexes shared the same (bpy) ${ }_{2}$ RuL platform; however, L was py-py (i.e., bpy), py- $f \mathrm{NHC}^{\mathrm{CH} 2 \mathrm{Ph}}$, and py-f $\mathrm{NHC} \mathrm{Me}^{\mathrm{Me}}$ in 1, 9, and 10, respectively, and it was ph-py (i.e., ppy), $\mathrm{ph}^{\mathrm{Br}}-\mathrm{NHC}$, $\mathrm{ph}^{\mathrm{OMe}}-\mathrm{MIC}^{\mathrm{Me}}$, and $\mathrm{ph}^{\mathrm{CN}}-\mathrm{MIC}^{\mathrm{Me}}$ in 5, 6, 7, and 8, respectively. These data imply that the most critical factor that determines the redox energetics in these photoredox catalysts is whether the ligand is phenyl or pyridine based. The observed trend that phenyl-containing complexes undergo easier metal-centered oxidation and their ligand-centered reduction is energetically more challenging than pyridine-based complexes agrees with the intuitive chemical notion that the carbanion contact atom of phenyl is a superior electron donor to pyridine's nitrogen leading to, for example, the stabilization of the metal center at higher oxidation states $[55,70,71]$. The independence of the reduction potentials of metal-centered processes on the nature of the carbene fragment implies that even if these carbenes are excellent $\sigma$-donors, their stabilization effect in the different metal oxidation states is apparently counteracted by the weakened $\mathrm{Ru}-\mathrm{N}$ bonds trans to these $\mathrm{Ru}-\mathrm{C}_{\text {carbene }}$ interactions. On the other hand, the finding that the energetics of ligand-centered redox events does not depend on the nature of $\mathrm{L}$, the carbene-containing ligand, suggests that the latter does not participate in the formally ligand-based reductions/oxidations of these (bpy) ${ }_{2}$ RuL-type complexes. This notion is unambiguously confirmed by subsequent analyses. 
In contrast to the former heteroleptic systems, the nature of the carbene ligands directly and unmistakably manifests in the redox properties of homoleptic systems, 1, 2, 3, and 4 (Table 2). For instance, the sharp decrease of the $\mathrm{Ru}(\mathrm{III}) / \mathrm{Ru}(\mathrm{II})$ reduction potential from $1.29 \mathrm{~V}\left[\mathrm{Ru}(\mathrm{bpy})_{3}\right]^{2+}$ (1) to 1.12 $\mathrm{V}, 0.68 \mathrm{~V}$ and $0.14 \mathrm{~V}$ in the parent $\left[\mathrm{Ru}(\mathrm{py}-\mathrm{NHC})_{3}\right]^{2+}(2),\left[\mathrm{Ru}(\mathrm{py}-\mathrm{MIC})_{3}\right]^{2+}(4)$, and $\left[\mathrm{Ru}(\mathrm{py}-a \mathrm{NHC})_{3}\right]^{2+}(3)$ systems, respectively, can be attributed to the increasing $\sigma$-donor properties of the carbene fragments leading to the extra stabilization of the $\mathrm{Ru}(\mathrm{III})$ over $\mathrm{Ru}(\mathrm{II})$. The same trend was observed for the excited-state metal-centered redox event of these complexes. The shift of $0.5 \mathrm{~V}$ when going from 3 to 4 is especially telltale for how the change of one atom in the ligand frame ( $\mathrm{N}$ to $\mathrm{CH}$ in this case) can affect the electronic properties of carbene groups and ligands. The very negative reduction potential of ligand-centered events (e.g., $-1.96 \mathrm{~V}$ in 2 with NHC groups and $-2.23 \mathrm{~V}$ in 3 with $a \mathrm{NHC}$ groups) indicates that these types of carbene ligands cannot efficiently stabilize additional electrons in their $\pi$-system, i.e., these groups have poor redox activity. This property also manifests in the excited-state reactivity, offering a significantly large thermodynamic driving force to extrude the ligand-centered electron in the ${ }^{3}$ MLCT state. This insight might help rationalizing the recent observation by Jalón and co-workers [16] that the homoleptic ruthenium-carbene complex A directly reacts with the co-catalysts through the oxidative quenching cycle instead of reacting with an electron donor (the sacrificial agent) first through the reductive quenching cycle. Finally, the results obtained for complexes $\mathbf{1 1}$ and $\mathbf{1 2}$ reveal that there was an additional significant prospective in controlling the redox energetics through other factors, like using more extended tridentate ligands and their different binding modes (e.g., meridional versus facial) to the metal. In 12, for example, it was interesting to see that the two NHC wingtip groups had the same effect on the $\mathrm{Ru}(\mathrm{III}) / \mathrm{Ru}(\mathrm{II})$ transition that was discussed for the $\left[\mathrm{Ru}(\mathrm{py}-\mathrm{NHC})_{3}\right]^{2+}$ system (2), while the tpy ligand of $\mathbf{1 2}$ offered stable states with ligand-centered radicals (i.e., ligand-centered reductions shifted towards more positive potentials with respect to bpy). As discussed below, the latter behavior can be attributed solely to the tpy ligand as the $\mathrm{C}^{\wedge} \mathrm{N}^{\wedge} \mathrm{C}$ carbene ligand does not participate in the ligand-centered redox events.

To gain detailed insight into the electronic structure changes during the reduction and oxidation steps of the quenching cycles and to further conceptualize some of the observed trends in the redox energetics, we analyzed the electron density difference maps, $\Delta \rho(\mathrm{r})$, corresponding to the five fundamental steps of the quenching cycles, such as $\mathrm{S}_{0} \rightarrow{ }^{3} \mathrm{MLCT},{ }^{3} \mathrm{MLCT} \rightarrow \mathrm{D}^{\text {red }}$, $\mathrm{D}^{\text {red }} \rightarrow \mathrm{S}_{0},{ }^{3} \mathrm{MLCT}$ $\rightarrow \mathrm{D}^{\mathrm{ox}}$ and $\mathrm{D}^{\mathrm{ox}} \rightarrow \mathrm{S}_{0}$. While electron density difference distributions have been utilized extensively to analyze electronic transitions upon photoexcitation and to distinguish MLCT, MC, and LLCT transitions, etc., its use to characterize the nature and detailed features of transitions that include outer-sphere electron transfer events was pioneered by us [68,69]. For a single electron reduction, for example, the density difference distribution $\Delta \rho(\mathrm{r})$ is evaluated as the electron density of the reduced state minus the electron density of the oxidized state which, if plotted in 3D together with the molecular frame, reveals the sites, functional groups, and atoms where charge accumulates or depletes upon the reduction process. The analysis has to be carried out at a constant geometry in practice, which is an acceptable approximation in the case of the studied systems as the molecular geometry only distorts marginally upon the reduction and oxidation of these species. Namely, as the metal-centered reduction or oxidation event involves a formally non-bonding $t_{2 g} d$-orbital; the geometry barely changes during the redox event, and such a notion can be clearly observed in Table 3 which lists the metal-ligand distances in the four states involved in the quenching cycles for three structurally different representative systems: $\mathbf{1}, \mathbf{1 0}$, and $\mathbf{1 2}$. In complex $\mathbf{6}$, for example, $\mathrm{Ru}-\mathrm{N}_{\text {pyridine }}$ bond distances have a maximum variation of $0.03 \AA$ through the four states, and this change is also characteristic for the metal-carbanion distances, whereas $\mathrm{Ru}-\mathrm{C}_{\text {carbene }}$ distances vary even less upon photoexcitation and redox events. An additional interesting finding revealed in Table 3 was the shorter $\mathrm{Ru}-\mathrm{C}_{\text {carbene }}$ bonds $(\mathrm{Ru}-\mathrm{X} 2)$ in the $\mathrm{D}^{\text {red }}$ state with $\mathrm{Ru}$ (II) than in $\mathrm{D}^{\mathrm{ox}}$ where the carbene binds to a $\mathrm{Ru}(\mathrm{III})$ center. Furthermore, as the redox active orbital of the ligand is delocalized, the ligand-centered $\mathrm{L}^{0} / \mathrm{L}^{-1}$ transitions induced only slight deformations in the ligand frame upon reduction, which we clearly demonstrated in our earlier studies on redox non-innocent and redox active ligands with similar 
features than the ligands investigated in this study $[68,69]$. These results support the notion that density difference distributions determined at the equilibrium structure of either the oxidized or reduced state characterize realistically the electronic structure changes of the corresponding redox event in the investigated photoredox platforms.

Table 3. Average Ru- $\mathrm{N}_{\text {pyridine, }} \mathrm{Ru}-\mathrm{C}_{\text {phenyl }}$, and $\mathrm{Ru}-\mathrm{C}_{\text {carbene }}$ distances (in $\AA$ ) in the four stationary points $\left(\mathrm{S}_{0}, \mathrm{~T}_{1}, \mathrm{D}^{\mathrm{ox}}, \mathrm{D}^{\text {red }}\right)$ of the oxidative and reductive photoredox cycles for $\left[\mathrm{Ru}(\mathrm{bpy})_{3}\right]^{2+}(\mathbf{1})$, $\left[\mathrm{Ru}(\text { bpy })_{2}\left(\text { py- } f \mathrm{NHC}^{\mathrm{Me}}\right)\right]^{2+}(\mathbf{1 0})$, and $\left[\mathrm{Ru}(\text { tpy })\left(\mathrm{C}^{\wedge} \mathrm{N}^{\wedge} \mathrm{C}\right)\right]^{2+}(\mathbf{1 2})$.

\begin{tabular}{|c|c|c|c|c|c|c|c|c|c|c|c|c|}
\hline \multirow{2}{*}{ Bond (Å) } & \multicolumn{4}{|c|}{$\left[\mathrm{Ru}(\mathrm{bpy})_{3}\right]^{2+}$} & \multicolumn{4}{|c|}{$\left[\mathrm{Ru}(\mathrm{bpy})_{2}\left(\mathrm{py}-f \mathrm{NHC}^{\mathrm{Me}}\right)\right]^{2+}$} & \multicolumn{4}{|c|}{$\left[\mathrm{Ru}\left(\text { tpy) }\left(\mathrm{C}^{\wedge} \mathrm{N}^{\wedge} \mathrm{C}\right)\right]^{2+}\right.$} \\
\hline & $\mathrm{S}_{0}$ & $\mathrm{~T}_{1}$ & $D^{o x}$ & $D^{\text {red }}$ & $\mathrm{S}_{0}$ & $\mathbf{T}_{1}$ & $D^{o x}$ & $D^{\text {red }}$ & $\mathrm{S}_{0}$ & $\mathbf{T}_{1}$ & $D^{o x}$ & $D^{\text {red }}$ \\
\hline $\mathrm{Ru}-\mathrm{X} 1$ & 2.058 & 2.058 & 2.070 & 2.050 & 2.075 & 2.083 & 2.078 & 2.066 & 2.090 & 2.114 & 2.110 & 2.055 \\
\hline $\mathrm{Ru}-\mathrm{X} 2$ & 2.058 & 2.058 & 2.070 & 2.050 & 1.990 & 1.999 & 1.987 & 1.965 & 2.059 & 2.057 & 2.065 & 2.050 \\
\hline $\mathrm{Ru}-\mathrm{N} 3$ & 2.058 & 2.059 & 2.070 & 2.050 & 2.058 & 2.049 & 2.066 & 2.051 & 2.063 & 2.075 & 2.075 & 2.061 \\
\hline Ru-N4 & 2.058 & 2.059 & 2.070 & 2.050 & 2.059 & 2.052 & 2.073 & 2.055 & 1.952 & 1.966 & 1.968 & 1.978 \\
\hline $\mathrm{Ru}-\mathrm{X5}$ & 2.058 & 2.059 & 2.070 & 2.050 & 2.124 & 2.126 & 2.145 & 2.121 & 2.059 & 2.064 & 2.066 & 2.049 \\
\hline $\mathrm{Ru}-\mathrm{N} 6$ & 2.058 & 2.059 & 2.070 & 2.050 & 2.065 & 2.061 & 2.082 & 2.059 & 2.061 & 2.074 & 2.081 & 2.060 \\
\hline
\end{tabular}

Figure 4 shows the electron density difference distribution, $\Delta \rho(\mathrm{r})$, for the photoexcitation process and subsequent redox events of the reductive quenching cycle for three representative photoredox catalysts, such as the homoleptic $\left[\mathrm{Ru}(\mathrm{bpy})_{3}\right]^{2+}(\mathbf{1})$, heteroleptic $\left[\mathrm{Ru}(\mathrm{bpy})_{2}\left(\mathrm{py}-\mathrm{fNHC} \mathrm{Ne}^{\mathrm{Me}}\right)\right]^{2+}$ (10), and $\left[\mathrm{Ru}(\operatorname{tpy})\left(\mathrm{C}^{\wedge} \mathrm{N}^{\wedge} \mathrm{C}\right)\right]^{2+}(\mathbf{1 2})$, with the tridentate terpyridine and $\mathrm{C}^{\wedge} \mathrm{N}^{\wedge} \mathrm{C}$ MIC-containing ligands. The analogous $\Delta \rho(\mathrm{r})$ maps of the oxidative quenching cycle are given in the Supplementary Materials (Figure S1). The $\Delta \rho(\mathrm{r})$ maps of the $\mathrm{S}_{0}{ }^{3} \mathrm{MLCT}\left(\mathrm{T}_{1}\right)$ processes (left, Figure 4 ) offer intuitive insights into the electronic changes induced by photon absorption and subsequent intersystem crossing (ISC) in these systems, revealing characteristic metal-to-ligand charge transfers in accordance with the MLCT nature of the triplet excited state. The depletion of electron density (red sites) at the metal and the accumulation of density (yellow regions) mostly at the ligand is a general feature in all the three systems when going from the $\mathrm{S}_{0}$ state to the ${ }^{3} \mathrm{MLCT}$ state.

Nevertheless, other relevant details can be deduced from the close inspection of the plots. For example, when accumulated on the bipyridine ligand(s) (e.g., in $\left.\left[\mathrm{Ru}(\mathrm{bpy})_{3}\right]^{2+}\right)$ the electron density is not delocalized to the backbone of the ligand(s) to the extent as perhaps expected on the delocalized nature of its LUMO. Instead, it remains "localized" at the N-C-C-N contact functionality of the ligand. This pattern of density accumulation was also observed for redox non-innocent benzoquinonediimine ligands upon reduction and was rationalized based on a superior electrostatic stabilization when the accumulated negative charge at the ligand remains in the proximity of the formally +3 metal, in contrast to being delocalized to the backbone of the ligand $[68,69]$. This density accumulation pattern at the ligand can be also observed for $\mathbf{1 0}$ and $\mathbf{1 2}$.

Probably the most spectacular insight revealed by this analysis is the disclosure of the localization of the transferred charge to bipyridine and terpyridine ligand(s) in heteroleptic carbene complexes. Namely, going from $\left[\mathrm{Ru}(\mathrm{bpy})_{3}\right]^{2+}$ to $\left[\mathrm{Ru}(\mathrm{bpy})_{2}\left(\text { py- } f \mathrm{NHC}^{\mathrm{Me}}\right)\right]^{2+}(\mathbf{1 0})$ and $\left[\mathrm{Ru}(\mathrm{tpy})\left(\mathrm{C}^{\wedge} \mathrm{N}^{\wedge} \mathrm{C}\right)\right]^{2+}(\mathbf{1 2})$, the charge transferred from the metal to the ligand which was delocalized uniformly amongst the three bpy ligands in $\left[\mathrm{Ru}(\mathrm{bpy})_{3}\right]^{2+}$, becoming localized to the two bpy ligands in $\left[\mathrm{Ru}(\mathrm{bpy})_{2}\left(\mathrm{py}-f \mathrm{NHC} \mathrm{Me}^{\mathrm{e}}\right)\right]^{2+}$ and to the tpy ligand in $\left[\mathrm{Ru}(\mathrm{tpy})\left(\mathrm{C}^{\wedge} \mathrm{N}^{\wedge} \mathrm{C}\right)\right]^{2+}(\mathbf{1 2})$. Accordingly, the involvement of the carbene-containing ligand into the photoexcitation was negligible. Of course, pyridine and carbenes differ in their electron affinities giving rise to this behavior of non-equivalent charge distribution in heteroleptic systems. Nevertheless, the sharp contrast between the contribution of carbenes and bpy to hosting the transferred charge was remarkable as revealed by Figure 4 . In homoleptic carbene complexes with three identical 
ligands (e.g., in 2, 3, and 4) similarly to $\left[\mathrm{Ru}(\mathrm{bpy})_{3}\right]^{2+}$, the transferred charge was delocalized throughout all ligands.
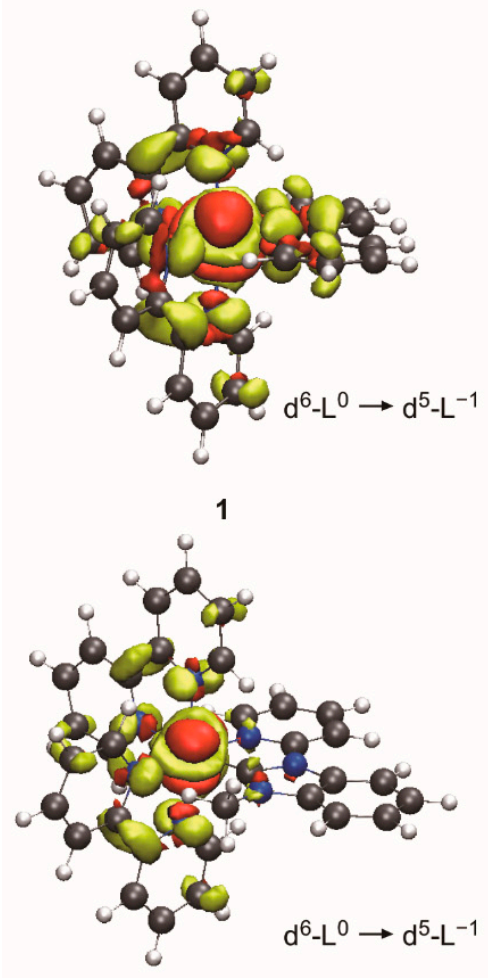

10

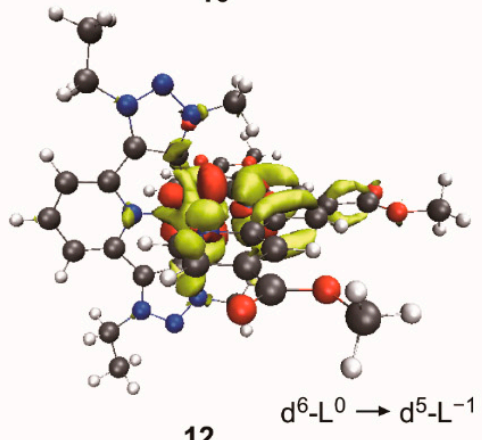

12

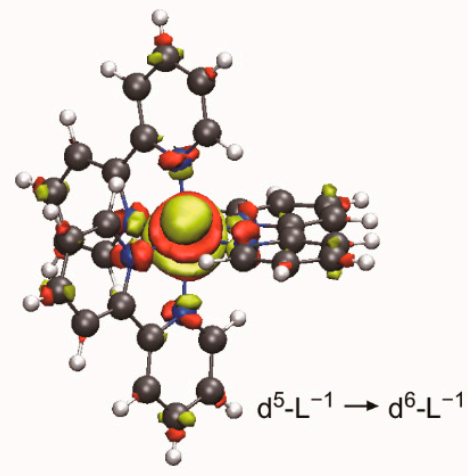

1

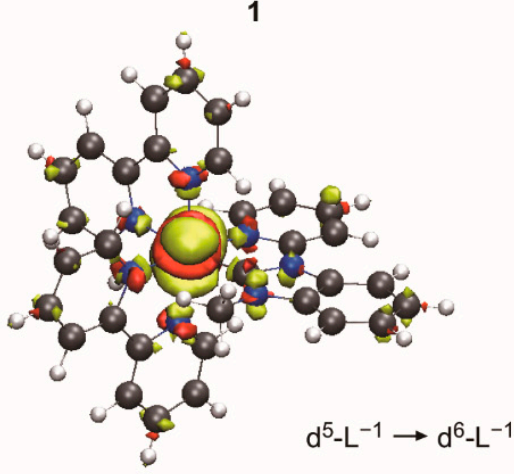

10

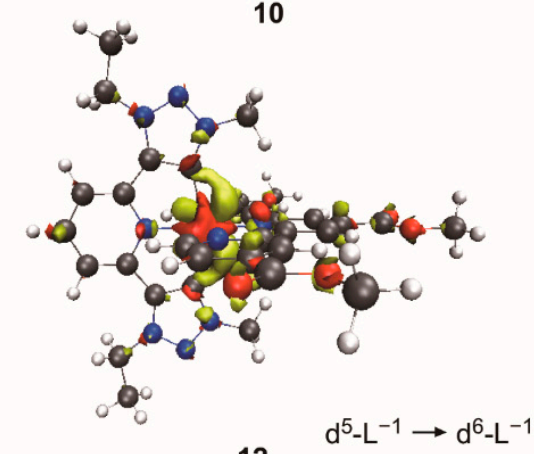

12
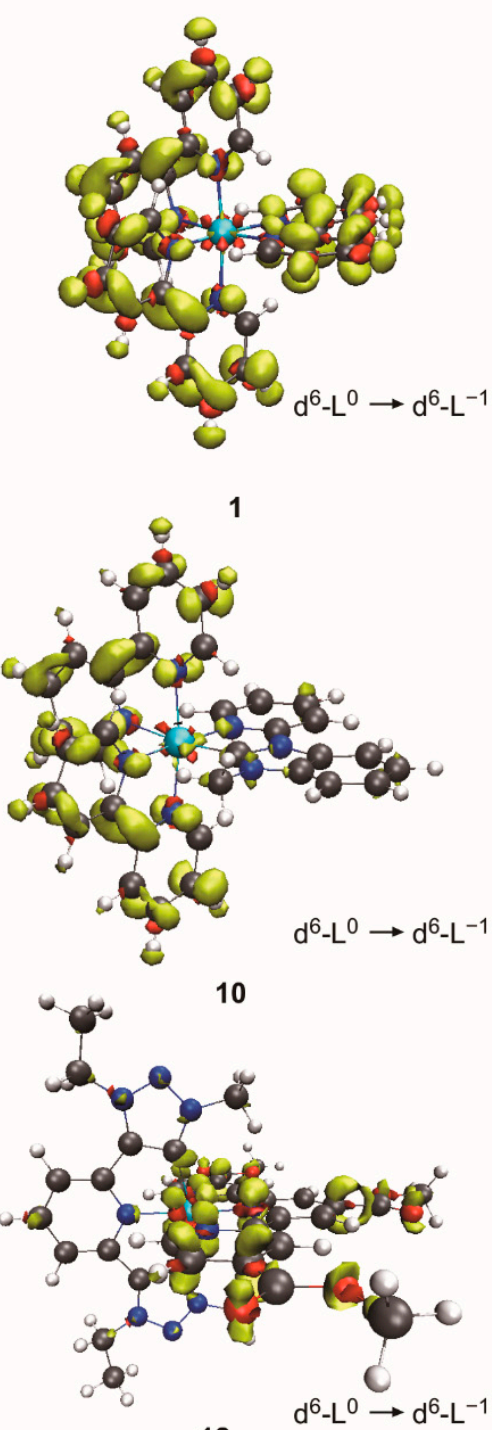

12

Figure 4. Electron density difference distributions, $\Delta \rho(\mathrm{r})$, corresponding to the $\mathrm{S}_{0} \rightarrow \mathrm{T}_{1}$ transition (left, inducing a formal $\mathrm{d}^{6} \mathrm{~L}^{0} \rightarrow \mathrm{d}^{5} \mathrm{~L}^{-1}$ electronic structure change) the first excited-state reduction step of the reductive quenching cycle (middle, $\mathrm{T}_{1} \rightarrow \mathrm{D}^{\text {red }}$ transition, inducing a formal $\mathrm{d}^{5} \mathrm{~L}^{-1} \rightarrow \mathrm{d}^{6} \mathrm{~L}^{-1}$ electronic structure change) and second ground-state oxidation step of the reductive quenching cycle (right, $\mathrm{D}^{\text {red }}$ $\rightarrow \mathrm{S}_{0}$ transition, inducing a formal $\mathrm{d}^{6} \mathrm{~L}^{-1} \rightarrow \mathrm{d}^{6} \mathrm{~L}^{0}$ electronic structure change) for 1,10 , and 12 . Note that the $\Delta \rho(\mathrm{r})$ map of the latter process is given for the reduction direction $\left(\mathrm{S}_{0} \rightarrow \mathrm{D}^{\text {red }}\right)$ for the sake of consistency.

Admittedly, besides the yellow (accumulation) lobes at the ligands, which clearly exhibit the features of $\pi$-symmetry redox active orbitals, some loss of electron density can also be witnessed at the ligand as implied by the red regions in certain cases. These red sites correspond to $\sigma$-symmetry with respect to the ligand frame (e.g., in $\left[\mathrm{Ru}(\mathrm{bpy})_{3}\right]^{2+}$ ), and they imply an enhanced $\sigma$-donation from the ligand to the metal when it formally changed from $\mathrm{Ru}(\mathrm{II})$ to $\mathrm{Ru}(\mathrm{III})$. This increased donation was also reflected by the directional accumulation (yellow) at the metal. 
The $\Delta \rho(\mathrm{r})$ maps corresponding to the two redox steps of the reductive quenching cycle, ${ }^{3} \mathrm{MLCT}$ to $\mathrm{D}^{\text {red }}$ and $\mathrm{D}^{\text {red }}$ to $\mathrm{S}_{0}$, are also given in Figure 4 for the three selected photoredox catalysts. These analyses were carried out at the equilibrium structure of the $S_{0}$ state of the complexes, and the approximation did not alter the conceptual insight offered by the analysis of the $\Delta \rho(\mathrm{r})$ maps.

The established photophysics and subsequent chemical processes imply a formal $\mathrm{d}^{5} / \mathrm{d}^{6}$ metal-based reduction for the first (excited state) step of the reductive quenching cycle whereas a conventional ligand-centered oxidation was expected for the $\mathrm{D}^{\text {red }} \rightarrow \mathrm{S}_{0}$ transition corresponding to the second step of this pathway. Indeed, Figure 4 clearly reveals a massive accumulation of electron density around the metal in each complex, aligning well with the consensus assignment of an excited-state $\mathrm{d}^{5} / \mathrm{d}^{6}$ transition. The electron density change maps corresponding to the second step also unambiguously demonstrated ligand-centered redox events in all systems with a minor or negligible contribution from the metal. Then again, the marginal contribution of carbene ligands, with respect to that of bipyridine and terpyridine to these ligand-centered redox events, can be clearly witnessed and which can be rationalized based on the superior redox activity and electron affinity of pyridine to carbenes. These insights also clarify the observation that the redox energetics of formal ligand-centered processes does not depend on the nature of the carbene ligands in heteroleptic systems.

Another intuitive way to monitor the electronic structure changes of open-shell species is using spin-density distributions $\left(\rho^{\mathrm{s}}(\mathrm{r})=\rho^{\alpha}(\mathrm{r})-\rho^{\beta}(\mathrm{r})\right)$ [72-74] and their changes upon a chemical process. Table 4 gives the atom $(\mathrm{Ru})$ - and fragment(ligand)-condensed spin density values in the ${ }^{3} \mathrm{MLCT}$, $\mathrm{D}^{\text {ox }}$, and $\mathrm{D}^{\text {red }}$ states for six representative systems and in the ${ }^{3} \mathrm{MC}$ state of homoleptic complexes $1-4$. The corresponding spin density values in the $\mathrm{S}_{0}$ state are zero by definition. This quantitative analysis has been carried out at the corresponding equilibrium geometry of each investigated state and, thus, it is not affected by the fixed geometry constraint applied in the EDD analysis. Spin density values of 0.7-1.0 at the ruthenium center, observed in ${ }^{3} \mathrm{MLCT}$ and $\mathrm{D}^{\mathrm{ox}}$ states, reveal a formal unpaired $\alpha$ electron at the metal, which indicates a $\mathrm{d}^{5}$ configuration, i.e., a $\mathrm{Ru}(\mathrm{III})$ oxidation state. The deviation from the nominal value of 1.0 was due to the $\pi$-donation from the ligand to the metal in the $\beta$ subspace (one of the $\pi$-symmetry $t_{2 g}$ orbitals is half-vacant) and to a minor extent to the $\pi$-back-donation from the metal to the ligand in the $\alpha$ subspace. The latter effect was plausibly negligible in the complexes investigated, as $\mathrm{Ru}(\mathrm{III})$ is a weak back-donor. Accordingly, the Ru-condensed values imply formal $\mathrm{Ru}(\mathrm{III})$ centers in the triplet ${ }^{3} \mathrm{MLCT}$ and doublet $\mathrm{D}^{\text {ox }}$ states, whereas the $\mathrm{d}^{6} \mathrm{Ru}(\mathrm{II})$ oxidation state was prevalent in the reduced $\mathrm{D}^{\text {red }}$ state, in accordance with the consensus formal assignments of these states. Similarly, ligand/fragment-condensed values close to 1 imply a formally one-electron reduced ligand or fragment, whereas fractional values describe the delocalization of the unpaired electron to other groups/metal.

The variation of the condensed spin-density values amongst the different states support explicitly the notions deduced above through the analysis of the density difference maps. For instance, going from ${ }^{3} \mathrm{MLCT}$ to $\mathrm{D}^{\text {red }}$ the spin-density at Ru decreases from $\sim 0.7$ in ${ }^{3} \mathrm{MLCT}$ to $\sim 0.0$ in $\mathrm{D}^{\text {red }}$, implying a fairly localized metal-centered $\mathrm{d}^{5} / \mathrm{d}^{6}$ transition. In contrast, the spin density distribution around the metal remains rather intact upon ${ }^{3} \mathrm{MLCT}$ to $\mathrm{D}^{\text {ox }}$ transition, while the mono-radical character of the ligand (spin-density value of 1-1.2) disappears, revealing a pure ligand-based oxidation. As also demonstrated above, the low spin density values $(<0.1)$ at the carbene fragments in all three oxidation states unambiguously demonstrate that these ligands do not participate actively in the photoexcitation and subsequent redox events in heteroleptic systems (e.g., in 8 and 10, Table 4). In these cases, all ligand-based changes are confined to the bipyridine ligands. In contrast, carbene ligands (py-NHC, py- $a \mathrm{NHC}$ and py-MIC) act as redox-active ligands in the MLCT and ligand-centered redox events of homoleptic catalysts $\mathbf{2}, 3$, and 4 . As one can see in Table 4, there is more spin density confined to the carbene groups ( 0.67 in 3 and 0.76 in 4 ) of these chelating ligands than to the pyridine fragment showing that the unpaired "extra" electron is significantly delocalized to the carbene fragment. Some of the contribution to this spin density at the carbene, however, originates from the $\pi$-donation from the carbene to the $\mathrm{d}^{5}$-metal in the $\beta$ subspace, which lowers the condensed spin-density value at the metal ( 0.68 in 3 and 0.73 in 4) and increases the spin density at the ligand. The spin densities of 0.19 and 
0.16 at the carbene in the $\mathrm{D}^{\mathrm{ox}}$ state (formally $\mathrm{d}^{5}-\mathrm{L}^{0}$ ) of $\mathbf{3}$ and $\mathbf{4}$, respectively, give a first-hand measure to the extent of this $\pi$-donation from the carbene to the $\mathrm{d}^{5}$ metal. Finally, we provided the condensed spin density values in the ${ }^{3} \mathrm{MC}$ state for some of these species, as we used this property to monitor electronic structure changes along the ${ }^{3} \mathrm{MLCT}$ to ${ }^{3} \mathrm{MC}$ transition which is discussed in the followings.

Table 4. Fragment/atom condensed spin density populations at the metal and at the ligand, separated into the constituting fragments, in the ${ }^{3} \mathrm{MLCT}, \mathrm{D}^{\mathrm{ox}}$, and $\mathrm{D}^{\text {red }}$ states of homoleptic complexes $1-4$ and heteroleptic systems 8 and 10, determined using the Löwdin method.

\begin{tabular}{|c|c|c|c|c|c|}
\hline Complex & Frag & ${ }^{3} \mathrm{MLCT}$ & $D^{\text {ox }}$ & $D^{\text {red }}$ & ${ }^{3} \mathrm{MC}$ \\
\hline \multirow{2}{*}{$\mathbf{1}\left[\mathrm{Ru}(\mathrm{bpy})_{3}\right]^{2+}$} & $\mathrm{Ru}$ & 0.827 & 0.853 & -0.028 & 1.668 \\
\hline & $\sum$ py & 1.172 & 0.145 & 1.009 & 0.331 \\
\hline \multirow{3}{*}{$2\left[\mathrm{Ru}(\mathrm{py}-\mathrm{NHC})_{3}\right]^{2+}$} & $\mathrm{Ru}$ & 0.657 & 0.652 & -0.029 & 1.204 \\
\hline & $\sum$ py & 0.814 & 0.277 & 0.270 & 0.321 \\
\hline & $\sum \mathrm{NHC}$ & 0.527 & 0.070 & 0.072 & 0.474 \\
\hline \multirow{3}{*}{$3\left[\mathrm{Ru}(\mathrm{py}-a \mathrm{NHC})_{3}\right]^{2+}$} & $\mathrm{Ru}$ & 0.679 & 0.715 & -0.019 & 1.236 \\
\hline & $\sum$ py & 0.648 & 0.094 & 0.523 & 0.347 \\
\hline & $\sum \mathrm{MIC}$ & 0.672 & 0.189 & 0.496 & 0.416 \\
\hline \multirow{3}{*}{$4\left[\mathrm{Ru}(\mathrm{py}-\mathrm{MIC})_{3}\right]^{2+}$} & $\mathrm{Ru}$ & 0.727 & 0.762 & -0.012 & 1.281 \\
\hline & $\sum$ py & 0.512 & 0.080 & 0.447 & 0.299 \\
\hline & $\sum \mathrm{MIC}$ & 0.759 & 0.156 & 0.565 & 0.419 \\
\hline \multirow{4}{*}{$8\left[\mathrm{Ru}(\mathrm{bpy})_{2}\left(\mathrm{ph}^{\mathrm{CN}}-\mathrm{MIC}^{\mathrm{Me}}\right]^{1+}\right.$} & $\mathrm{Ru}$ & 0.824 & 0.758 & -0.007 & \\
\hline & $\sum$ py & 1.038 & 0.033 & 0.962 & \\
\hline & $\mathrm{R}-\mathrm{Ph}$ & 0.032 & 0.171 & 0.018 & \\
\hline & R-MIC & 0.104 & 0.036 & 0.026 & \\
\hline \multirow{4}{*}{$10\left[\mathrm{Ru}(\mathrm{bpy})_{2}\left(\mathrm{py}-f \mathrm{NHC}^{\mathrm{Me}}\right)\right]^{2+}$} & $\mathrm{Ru}$ & 0.753 & 0.633 & -0.011 & \\
\hline & $\sum$ py & 1.116 & 0.055 & 0.992 & \\
\hline & R-py & 0.025 & 0.006 & 0.010 & \\
\hline & R-NHC & 0.105 & 0.014 & 0.008 & \\
\hline
\end{tabular}

Beyond the above described photophysics and redox properties, another critical property of efficient photoredox catalysts is the long lifetime ( $\sim \mu \mathrm{s})$ of the ${ }^{3}$ MLCT state of these complexes, which allows these species to engage in intermolecular collisions and reactions in the excited state [75]. Both radiative and non-radiative processes contribute to the decay of the ${ }^{3} \mathrm{MLCT}$ state, and these processes, together with the lifetime, depend significantly on other external factors, for example, on the solvent $[18,76,77]$. It has been demonstrated, for instance, that $80 \%$ of triplet MLCT excited-state ${ }^{*}\left[\mathrm{Ru}(\mathrm{bpy})_{3}\right]^{2+}$ returns to the ground state through the ${ }^{3} \mathrm{MC}$ state following a very efficient non-radiative pathway [78]. Accordingly, if the transition from the ${ }^{3} \mathrm{MLCT}$ to the ${ }^{3} \mathrm{MC}$ state is fast (i.e., a small activation barrier separates these states), the overall deactivation proceeds at high rates [79-82]. In regard to the ${ }^{3} \mathrm{MLCT}$ to ${ }^{3} \mathrm{MC}$ transition, one has to realize that the $\mathrm{t}_{2 \mathrm{~g}} \mathrm{~d}$ orbital set cannot host another $\alpha$ electron in the ${ }^{3} \mathrm{MC}$ state and one of the $\mathrm{e}_{\mathrm{g}}{ }^{*} \mathrm{~d}$ orbital, typically the $\mathrm{d}_{\mathrm{z}}{ }^{2}$, is necessarily populated by an electron in this state. The formally metal-based $\mathrm{d}_{\mathrm{z}}{ }^{2}$ is anti-bonding along the axial M-L interactions in an octahedral field, and its population results in a repulsion along the $\mathrm{M}-\mathrm{L}$ bond and, concomitantly, to a characteristic elongation of the axial bonds [14]. Accordingly, the geometry around the metal is quite different in the ${ }^{3} \mathrm{MC}$ and ${ }^{3} \mathrm{MLCT}$ states which means, from a computational viewpoint, that these two triplet states appear as well-defined local minima on the triplet PES and the corresponding connecting transition state also has acute features that characterize the elongation of the axial bonds [83,84]. These 
notions can be clearly recognized in Figure 5 showing the structure of ${ }^{3} \mathrm{MLCT},{ }^{3} \mathrm{TS}$, and ${ }^{3} \mathrm{MC}$ states of homoleptic systems 1, 2, and 3, calculated at the PBE/Def2-TZVP(-f) level of theory, given together with their gas phase and solution-state (in acetonitrile) relative energies to ${ }^{3} \mathrm{MLCT}$.
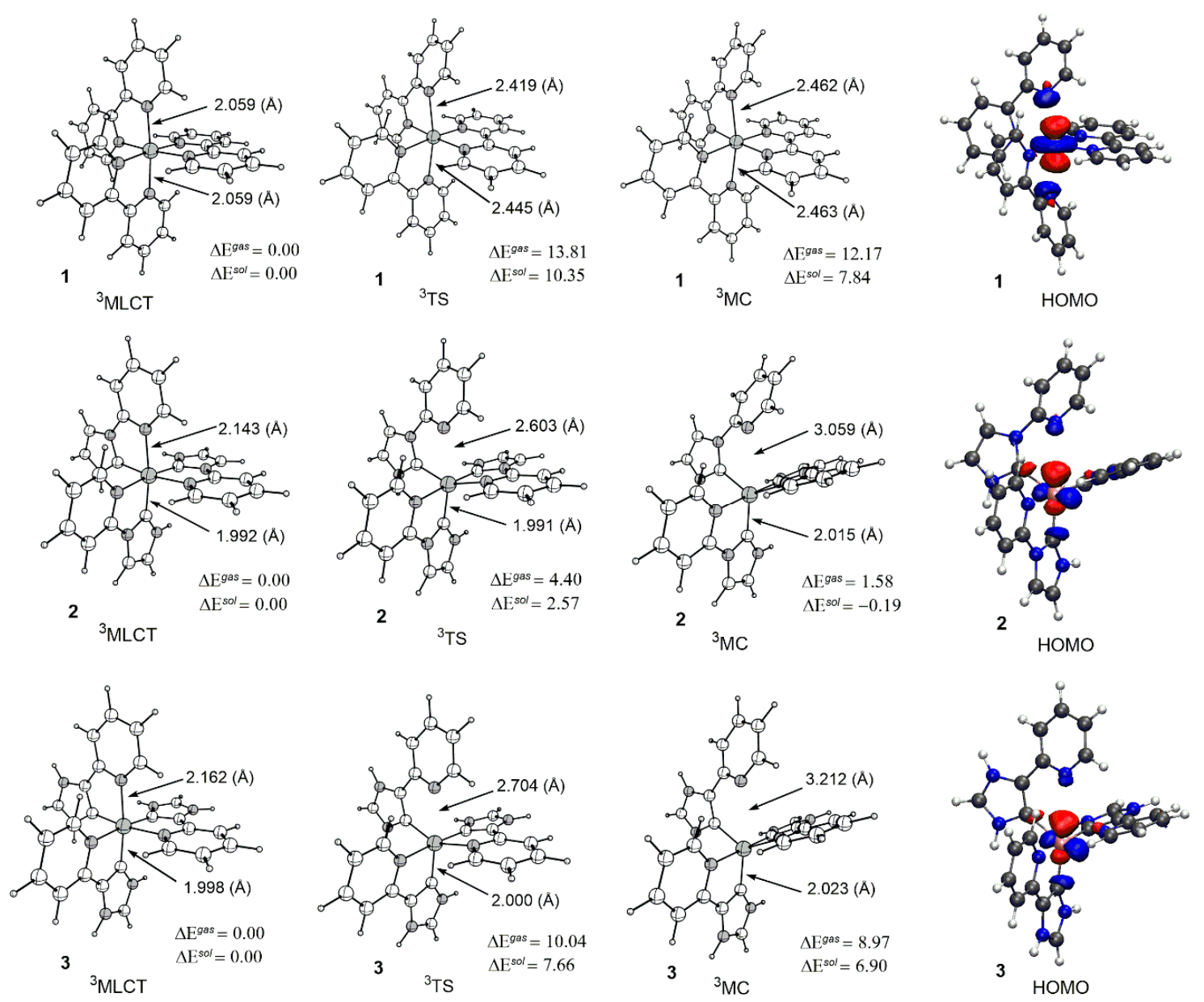

Figure 5. Equilibrium structure and relative gas phase and solution-state energy of ${ }^{3} \mathrm{MLCT},{ }^{3} \mathrm{TS}$ and ${ }^{3} \mathrm{MC}$ states and highest semi-occupied QRO of ${ }^{3} \mathrm{MC}$ state of homoleptic complexes 1: $\left[\mathrm{Ru}(\mathrm{bpy})_{3}\right]^{2+}, \mathbf{2}$ : $\left[\mathrm{Ru}(\mathrm{py}-\mathrm{NHC})_{3}\right]^{2+}$, and 3: $\left[\mathrm{Ru}(\mathrm{py}-a \mathrm{NHC})_{3}\right]^{2+}$. Relative energies are given in $\mathrm{kcal} \mathrm{mol}^{-1}$.

As hypothesized based on the formal electronic structure of the ${ }^{3} \mathrm{MC}$ state, the structure of this state was indeed significantly distorted along the axial axis for all three systems shown in Figure 5. For example, both axial $\mathrm{Ru}-\mathrm{N}_{\text {pyridine }}$ bonds elongated by about $0.4 \AA$ in the case of $\left[\mathrm{Ru}(\mathrm{bpy})_{3}\right]^{2+}$ during the ${ }^{3} \mathrm{MLCT}$ to ${ }^{3} \mathrm{MC}$ transition (Figure 5). In this analysis, we scrutinized only homoleptic systems with three identical $\mathrm{N}-\mathrm{Ru}-\mathrm{N}$ or $\mathrm{N}-\mathrm{Ru}-\mathrm{C}_{\text {carbene }}$ axes to limit the conformational possibilities of the ${ }^{3} \mathrm{MC}$ and ${ }^{3} \mathrm{TS}$ states to only one and be able to reveal the conceptual differences triggered by Ru- $\mathrm{N}_{\text {pyridine }}$ versus $\mathrm{Ru}-\mathrm{C}_{\text {carbene }}$ bonds in the ${ }^{3} \mathrm{MLCT}$ to ${ }^{3} \mathrm{MC}$ transition. Side-by-side comparison of the ${ }^{3} \mathrm{MC}$ states of 1, 2, and 3, for instance, revealed profound differences between the systems with trans $\mathrm{N}-\mathrm{Ru}-\mathrm{N}$ and $\mathrm{N}-\mathrm{Ru}-\mathrm{C}_{\text {carbene }}$ interactions in contrast to the symmetric elongation of the $\mathrm{N}-\mathrm{Ru}$ bonds along the $\mathrm{N}-\mathrm{Ru}-\mathrm{N}$ axis in $\mathbf{1}$; the $\mathrm{Ru}-\mathrm{C}_{\text {carbene }}$ interactions in $\mathbf{2}$ and $\mathbf{3}$ remained practically intact upon the ${ }^{3} \mathrm{MLCT}$ to ${ }^{3} \mathrm{MC}$ transition, and all the chemical changes (reduction of the metal center in an intermediate-spin fashion) accumulated along the $\mathrm{Ru}-\mathrm{N}$ bond trans to the carbene. The latter bond elongated by about $0.9 \AA$ and $1.1 \AA$ in the ${ }^{3} \mathrm{MC}$ state of $\mathbf{2}$ and 3, respectively. The corresponding electronic structure deformation can be rationalized by a strong hybridization of the $\mathrm{d}_{\mathrm{z}}{ }^{2}$ orbital with the $5 \mathrm{p}_{\mathrm{z}}(\mathrm{Ru})$ atomic orbital and it also gains a " $-\mathrm{x}^{2}$ " character in $\mathbf{2}$ and $\mathbf{3}$ which is also reflected by the spatial distribution 
of the quasi-restricted orbital (QRO) representing the half-filled d-orbital (HOMO in all three cases) along the $z$-axis (Figure 5).

The transition states corresponding to the ${ }^{3} \mathrm{MLCT}$ to ${ }^{3} \mathrm{MC}$ transition of the systems also exhibited these structural feature differences. Namely, a symmetric stretching of $\mathrm{N}-\mathrm{Ru}-\mathrm{N}$ was revealed in ${ }^{3} \mathrm{TS}$ of 1 , whereas an asymmetric, $\mathrm{Ru}-\mathrm{N}$-centered bond breaking along the $\mathrm{N}-\mathrm{Ru}-\mathrm{C}_{\text {carbene }}$ axis was taking place in the ${ }^{3} \mathrm{TS}$ transition state of $\mathbf{2}$ and $\mathbf{3}$. In addition, while the transition state of complex $\mathbf{1}$ can be termed as late due to the axial $\mathrm{Ru}-\mathrm{N}$ distances being close to the values in the "product" ${ }^{3} \mathrm{MC}$ state, the breaking Ru-N bond had distances of $2.6 \AA$ and $2.7 \AA$ in 2 and 3, respectively, indicating a mid-TS in these carbene ligand-containing systems. These conceptual differences between the ${ }^{3} \mathrm{MC}$ states and corresponding transition states may be well explained by the strong $\sigma$-donor nature of the carbene groups. As discussed above for the geometries of the $\mathrm{S}_{0}$ states, superior $\sigma$-donor carbenes form strong (and short) $\mathrm{Ru}-\mathrm{C}_{\text {carbene }}$ bonds which are energetically disadvantageous to break or weaken and which lead to stable $3 \mathrm{MC}$ states in which these $\mathrm{Ru}-\mathrm{C}_{\text {carbene }}$ bonds remain short, strong, and stabilizing. At the same time, the "extra" electron that the metal accepts from the ligand through the ${ }^{3} \mathrm{MLCT}$ to ${ }^{3} \mathrm{MC}$ transition gets accumulated along the $\mathrm{Ru} \cdots \mathrm{N}$ internuclear axis trans to the carbene (facilitated by $\mathrm{p}_{z} \mathrm{~d}_{\mathrm{z}}{ }^{2}$ hybridization and extension to a perpendicular axis $(\mathrm{x})$ ), without any delocalization towards the $\mathrm{Ru}-\mathrm{C}_{\text {carbene }}$ site. The notion that carbene ligands stabilize the ${ }^{3} \mathrm{MC}$ state over ${ }^{3} \mathrm{MLCT}$ in comparison to polypyridine ligands through the same electronic effect can be indeed seen in the calculated relative stabilities (Figure 5). Accordingly, the solution-state (gas phase) relative energy of ${ }^{3} \mathrm{MC}$ state to ${ }^{3} \mathrm{MLCT}$ decreased from $7.8(12.2) \mathrm{kcal} \mathrm{mol}^{-1}$ in $\mathbf{1}$ to -0.2 (1.6) $\mathrm{kcal} \mathrm{mol}^{-1}$ in 2 and to 6.9 and $9.0 \mathrm{kcal} \mathrm{mol}^{-1}$ in system 3 . The relative transition state energies exhibited an analogous trend, i.e., the activation barrier was lowered going from the pyridine-ruthenium system $\mathbf{1}$ to the carbene complexes $\mathbf{2}$ and 3. This finding might sound somewhat counterintuitive at first, as the general concept is that strong $\mathrm{Ru}-\mathrm{C}_{\text {carbene }}$ bonds resist bond breaking/stretching, which leads to higher activation barriers and longer triplet state lifetimes. Apparently, $\mathrm{Ru}-\mathrm{C}_{\text {carbene }}$ bonds indeed resist bond stretching, nevertheless, it is easier to break the $\mathrm{Ru}-\mathrm{N}_{\text {pyridine }}$ bond trans to carbenes as in $\mathrm{N}-\mathrm{Ru}-\mathrm{N}$ type axes, which might manifest in a facile non-radiate decay through the ${ }^{3} \mathrm{MLCT}$ to ${ }^{3} \mathrm{MC}$ path. The particularly low activation barrier of $2.57 \mathrm{kcal} \mathrm{mol}^{-1}$ in the case of complex 2 might account for the observation of Chung and co-workers [62] that complex "is nonemissive in acetonitrile at room temperature".

In 2010, an innovative technique, the non-covalent interaction (NCI) index, based on the correlation of the electron density and the reduced density gradient at any given point of space was introduced by Yang and co-workers [85] to identify and characterize weak chemical interactions $[85,86]$. This method has been already successfully used for distinguishing hydrogen bonds, halogen bonds, $\pi-\pi$ stacking, van der Waals interactions, steric repulsions, and other types of weak interactions in various systems $[87,88]$. Despite its great success in describing weak interactions in complex environments, to our best knowledge, no study on putative non-covalent interactions in photoredox catalysts has been carried out with this technique so far.

As the presence of inter-ligand weak interactions has been postulated in these systems, we were especially interested in the new insights that the NCI method may provide in the studied complexes. Plotting the low-gradient/low-density region points for the $\mathrm{S}_{0}$ state in real space with respect to the molecular frame of the complexes indeed reveals certain weak ligand-ligand interactions, from which representative examples are shown in Figure 6. Complex $\mathbf{6}$ and $\mathbf{1 0}$ demonstrate that alpha $\mathrm{C}_{\alpha}-\mathrm{H}$ bonds of bpy are oriented ideally to develop weak $\mathrm{C}-\mathrm{H} \cdots \mathrm{C}_{\text {carbene, }} \mathrm{C}-\mathrm{H} \cdots \mathrm{C}_{\text {phenyl }}$ and $\mathrm{C}-\mathrm{H} \cdots \mathrm{N}_{\text {pyridine }}$ interactions with the donor atoms of the other ligands, which can be witnessed in the localized green "plates" between the interacting regions. In both of these complexes, the wingtip group of the carbene fragments also engages in dispersion-like alkyl $\cdots$ pyridine (in 6) and aryl $\cdots$ pyridine $\pi-\pi$ stacking (in 10) interactions implied by the extended green surfaces between these sites. Complex $\mathbf{1 1}$ exemplifies that massive $\pi-\pi$ stacking can also emerge among the extended aromatic fragments of ligands, in which instances these weak interactions gain a non-negligible secondary role in determining the molecular structure. This notion was clearly supported by DFT calculations carried out with and 
without dispersion correction for 11, giving equilibrium structures with notable differences, dispersion corrected DFT structures being truthful to the X-ray geometry [77]. The extent of such inter-ligand weak interactions also depend profoundly on their binding mode to the metal as revealed by the significant differences between $\mathbf{1 1}$ and $[\mathrm{Ru}(\mathrm{tpy})(\mathrm{pmi})]^{2+}$; the meridional arrangement in the latter detrimentally limited the ligands in developing $\pi-\pi$ interactions through their backbone chains or groups, and only the wingtip groups were oriented preferably to interact with the other ligand(s) in the system. In contrast to $[\mathrm{Ru}(\mathrm{tpy})(\mathrm{pmi})]^{2+}$, the facial binding in $\mathbf{1 1}$ directly facilitated the through-space interaction of the extended aromatic backbone groups of the two ligands as can be clearly seen in Figure 6.

According to these findings offered by the NCI method, indeed many types of weak intra-ligand interactions emerge in classical and carbene-based photoredox catalysts which might even play a secondary role in determining the ultimate geometry of the complex. Our general experience with these kinds of weak interactions, however, is that they do not change notably along the photoredox quenching cycles as the overall geometry of the involved four states, $\mathrm{S}_{0},{ }^{3} \mathrm{MLCT}$, $\mathrm{D}^{\text {ox }}$ and $\mathrm{D}^{\text {red }}$, is very similar as discussed above for Table 3 . Hence, their contribution to the redox energetics is negligible, i.e., the contribution of weak interactions to the stability cancels out when calculating $\Delta G^{s o l}$ values for the different redox events. Their effect on the quenching dynamics, vibrations, radiative, and non-radiative decay processes of the ${ }^{3} \mathrm{MLCT}$ state and concomitantly on the lifetime of the ${ }^{3} \mathrm{MLCT}$ state is plausibly not negligible; however, it is admittedly hard to judge from this simple NCI analysis and needs further investigation.
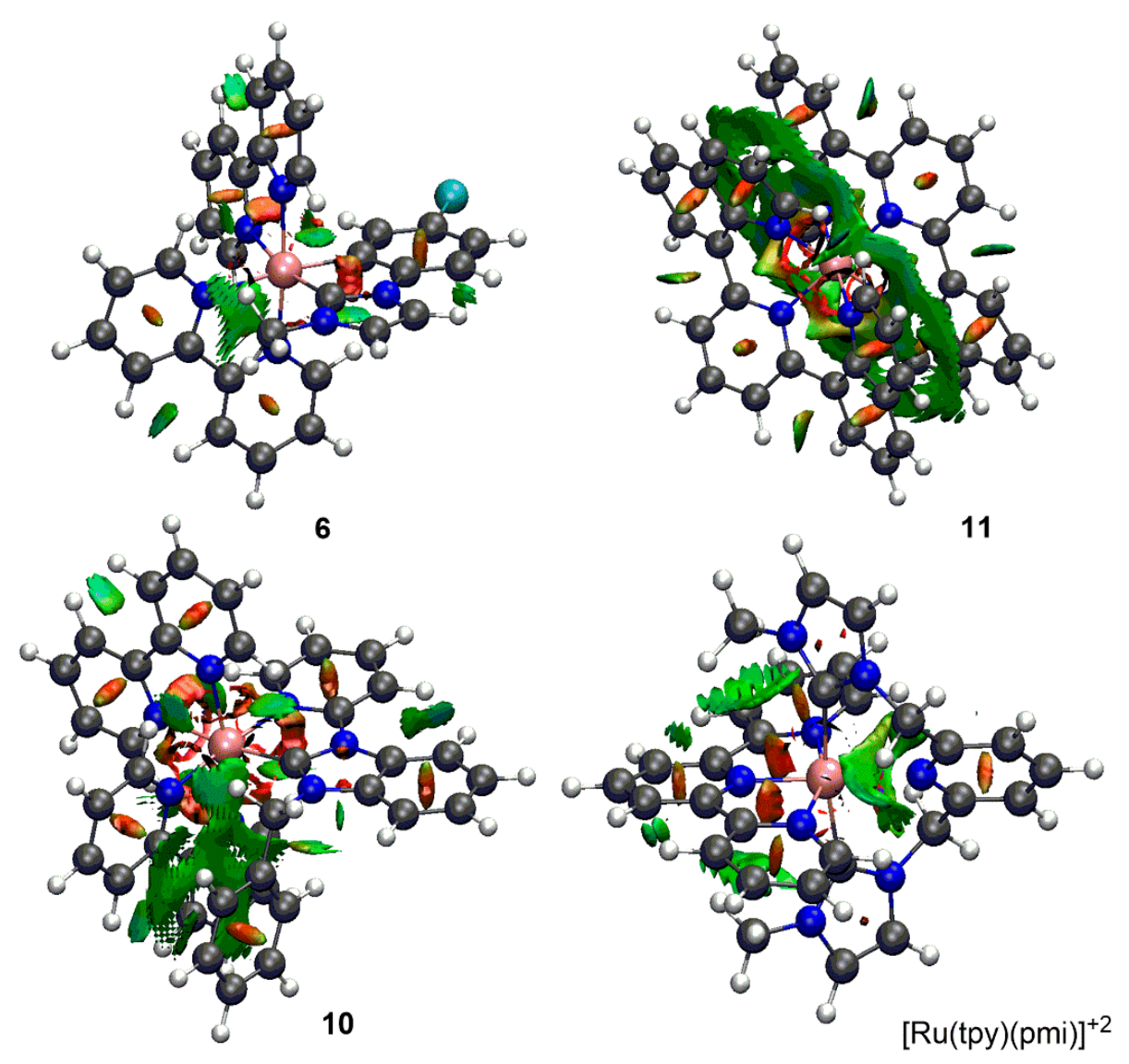

Figure 6. NCI isosurfaces $\left(s=0.4\right.$ a.u.) of complexes $\mathbf{6 , 1 0 , 1 1}$, and $[\mathrm{Ru}(\mathrm{tpy})(\mathrm{pmi})]^{2+}$ in their respective $\mathrm{S}_{0}$ state. Color coding of NCI surfaces: blue - attraction, green—van der Waals interaction (very weak attraction); and red-repulsion. The pmi ligand is 1,1'-[2,6-pyridinediylbis(methylene)]bis[3-methylimidazolium] in $[\operatorname{Ru}(\text { tpy })(\text { pmi })]^{2+}$. 


\section{Materials and Methods}

Density functional theory was implemented in ORCA (version 4.0.1.2, Max-Planck-Institute for Chemical Energy Conversion, Mülheim a. d. Ruhr, Germany, 2017) was utilized for all calculations in this study [89]. Geometry optimizations were carried out using the non-truncated models of the investigated transition metal complexes and the gradient-corrected PBE [90,91] functional together with the Def2-TZVP(-f) [92] basis set at a grid set denoted as Grid4. The Def2-ECP [93] effective core potential for Ru was built in the basis set by default which also aimed to account for the relativistic effects at the ruthenium center. In addition, the resolution of identity (RI) approximation was applied to accelerate geometry optimizations [94]. Dispersion was considered through Grimme's D3 [95] method in combination with the Becke-Johnson damping scheme [95] at short distances (D3BJ) in all calculations including the geometry optimizations. Analytical vibrational frequency calculations were carried out at the same level of theory as for the optimizations (PBE/Def2-TZVP(-f), Grid4) to validate that the optimized structures corresponding to minima or transition states of the potential energy surface (PES). Also, thermodynamic corrections to the electronic energy were obtained within the ideal gas-rigid rotor-harmonic oscillator approximation at $\mathrm{T}=273.15 \mathrm{~K}$. The energy of the examined structures was re-evaluated and their wavefunctions were refined through single points calculations at the TPSSh/Def2-TZVP level of theory without approximating the integrals with RI or RIJCOSX and maintaining D3BJ and Grid4 grid.

Solvation energy was computed using the SMD [96] implicit solvation model as implemented in ORCA at the gas-phase equilibrium structures at the TPSSh-D3/Def2-TZVP level of theory, using the same parameters of the single point calculations. We utilized the solvent accessible surface (SAS) method to create the cavity surface around the molecules, whereas the atomic radii of the default

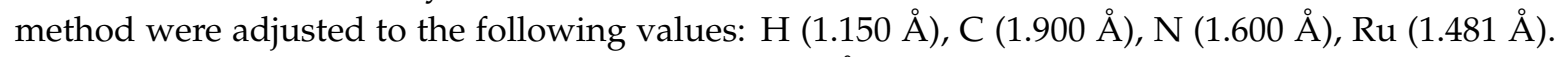
Acetonitrile was used as solvent with a radius of $2.19 \AA$.

We followed the established procedure for computing redox potentials as detailed by Roy et al. [97] and Baik and Friesner [98]. By definition, the standard absolute half-cell potential $\left(\mathrm{E}^{0}\right)$ was evaluated as:

$$
E^{0}\left(A / A^{-}\right)=\frac{-\Delta \mathrm{G}^{\mathrm{sol} 0}\left(A / A^{-}\right)}{n F}
$$

For the general reduction process:

$$
A+e^{-} \rightarrow A^{-}
$$

where $\Delta \mathrm{G}^{\text {sol }}$ is the solution-state Gibbs free energy of species $\mathrm{A}^{-}$minus that of $\mathrm{A} ; n$ is the number of moles of electrons transferred $(n=1)$, and $\mathrm{F}$ is the Faraday constant. $\Delta \mathrm{G}^{\text {sol } 0}$ was evaluated through the Born-Haber thermodynamic cycle [99] using gas phase equilibrium structures and thermodynamic corrections computed at the gas phase equilibrium structures. Gas-phase Gibbs free energy values were corrected by solvation energies to obtain solution-state Gibbs free energies of the individual species. We used the standard calomel electrode (SCE) as reference to calculate reduction potentials from the computed half-cell potentials as:

$$
E^{0}=E^{0}\left(A / A^{-}\right)-E^{0}(S C E)
$$

We used the value of $4.429 \mathrm{~V}$ for SCE established and verified recently by Demissie, Ruud, and Hansen [47]. For the electron density difference analysis, we used the wavefunctions obtained at the TPSSh/Def2-TZVP level of theory and Grid4 grid and computed at the equilibrium structure of the ground $\mathrm{S}_{0}$ state. Standard cube files of electron densities with grid dimensions of $80 \times 80 \times 80$ for each electronic state were generated with the orca_plot script, whereas the Multiwfn 3.7 [100] package was used to create the density differences for the $\mathrm{d}^{6} \mathrm{~L}^{-1}-\mathrm{d}^{5} \mathrm{~L}^{-1}, \mathrm{~d}^{6} \mathrm{~L}^{-1}-\mathrm{d}^{6} \mathrm{~L}^{0}$, and $\mathrm{d}^{5} \mathrm{~L}^{-1}-\mathrm{d}^{6} \mathrm{~L}^{0}$ processes as shown in Figure 4. The $\Delta \rho(\mathrm{r})$ maps were visualized using VMD 1.9.1 [101]. 
Non-covalent interaction (NCI) surfaces, introduced by Yang and Contreras-García [85,86], were calculated using PBE/Def2-TZVP (-f) densities and the Multiwfn (version 3.7) program (with all other computational details identical to that used for generating EDD maps). The NCI method was centered at the relationship of the reduced density gradient, s, and the electron density, $\rho$; in the case of any type of weak interaction present in the system, a characteristic signal emerges at the low-density/low-gradient values. The sign of the second component of the Laplacian along the three principal axes of maximal variation was used to decide whether a weak interaction is attractive or repulsive in line with common practice.

\section{Conclusions}

In conclusion, in this computational study, we systematically investigated the photoredox properties of twelve ruthenium-carbene and -polypyridine transition metal complexes using density functional theory. Through a direct comparison to experimental data, we demonstrated an efficient method based on the combination of the PBE functional with Grimme's D3 method and a balanced triple- $\zeta$ basis set that provided realistic molecular structures of these photoredox catalysts. We also validated a computational protocol based on the TPPSh functional and a re-parameterized SMD solvation model for solution-state Gibbs energies allowing the simulations of the ground-state redox energetics of metal- and ligand-centered electron transfer events within $0.15 \mathrm{~V}$. The results also revealed that the relative Gibbs free energy of the ${ }^{3} \mathrm{MLCT}$ state can be realistically computed using standard ground-state DFT without the necessity for time-dependent techniques, allowing the accurate calculation of the excited state redox potentials of these systems. Analysis of the obtained reduction potential values revealed that NHC and MIC carbenes have similar effects on the reduction potentials of $\mathrm{Ru}(\mathrm{III}) / \mathrm{Ru}(\mathrm{II})$ transitions as pyridine, while the pyridine/phenyl exchange has a significant effect on the redox energetics of ligand-centered events. In heteroleptic (bpy) ${ }_{2} \mathrm{Ru}(\mathrm{II}) \mathrm{L}$-type systems, the carbene-containing L ligand did not participate in the ligand-centered redox events and, accordingly, did not influence the corresponding reduction potentials. In contrast, the modest redox-active nature of carbenes manifested in negative reduction potentials in the ligand-centered redox events of homoleptic complexes.

We also thoroughly analyzed the electron density difference distributions and atom/fragment condensed spin density values corresponding to the $S_{0}$ to ${ }^{3} \mathrm{MLCT}$ electronic transition and the redox events of the reductive quenching cycle of representative systems. Amongst other details, the characteristic nature of MLCT transition, metal-centered reduction, and ligand-centered oxidation can be clearly witnessed in these $\Delta \rho(\mathrm{r})$ maps. The localization of the ligand-centered redox events to bipyridine and terpyridine was revealed for the heteroleptic (bpy) ${ }_{2} \mathrm{Ru}(\mathrm{II}) \mathrm{L}$-type systems. The analysis of the ${ }^{3} \mathrm{MLCT}$ to ${ }^{3} \mathrm{MC}$ transitions also exposed characteristic differences between carbene and pyridine groups; in contrast to $\mathrm{Ru}-\mathrm{N}$, the strong $\mathrm{Ru}-\mathrm{C}_{\text {carbene }}$ bonds did not elongate from ${ }^{3} \mathrm{MLCT}$ to ${ }^{3} \mathrm{MC}$ transitions. The latter interactions, however, induced an easier $\mathrm{Ru}-\mathrm{N}$ stretching in trans positions which eventually led to a more stable $3 \mathrm{MC}$ state and lowered activation barriers in homoleptic carbene complexes. Finally, NCI analysis showed specific weak intra-ligand interactions, including $\pi-\pi$ stacking and $\mathrm{C}-\mathrm{H} \cdots$ arbene ones.

Supplementary Materials: Cartesian coordinates of equilibrium structures in all spin and oxidation states together with the corresponding electronic energies are provided in the SM. This material is available free of charge via the Internet at https://www.mdpi.com/journal/catalysts/special_issues/NHC.

Author Contributions: E.M. carried out the calculations and organized the obtained data, collected and standardized experimental records from literature, and created figures and tables and composed the supporting information. B.P. rationalized the results, wrote the text of the manuscript, and played a supervising role. All authors have read and agreed to the published version of the manuscript.

Funding: This research was funded by FONDECYT through the FONDECYT Regular program with grant number 325938.

Acknowledgments: E.M. is grateful to Universidad Técnica Federico Santa María and Universidad de Valparaiso for the PhD scholarship in the joint doctorate in chemistry program of the two institutions. We also thank the 
Centro Científico Tecnológico (CCTVal) for the computational resources and technical support provided free of charge.

Conflicts of Interest: The authors declare no conflict of interest.

\section{References}

1. Prier, C.K.; Rankic, D.A.; Macmillan, D.W.C. Visible Light Photoredox Catalysis with Transition Metal Complexes: Applications in Organic Synthesis. Chem. Rev. 2013, 113, 5322-5363. [CrossRef] [PubMed]

2. Narayanam, J.M.R.; Stephenson, C.R.J. Visible light photoredox catalysis: Applications in organic synthesis. Chem. Soc. Rev. 2011, 40, 102-113. [CrossRef] [PubMed]

3. Tucker, J.W.; Stephenson, C.R.J. Shining light on photoredox catalysis: Theory and synthetic applications. J. Org. Chem. 2012, 77, 1617-1622. [CrossRef] [PubMed]

4. Teegardin, K.; Day, J.I.; Chan, J.; Weaver, J. Advances in Photocatalysis: A Microreview of Visible Light Mediated Ruthenium and Iridium Catalyzed Organic Transformations. Org. Process Res. Dev. 2016, 20, 1156-1163. [CrossRef]

5. Skubi, K.L.; Blum, T.R.; Yoon, T.P. Dual Catalysis Strategies in Photochemical Synthesis. Chem. Rev. 2016, 116, 10035-10074. [CrossRef]

6. Shaw, M.H.; Twilton, J.; Macmillan, D.W.C. Photoredox Catalysis in Organic Chemistry. J. Org. Chem. 2016, 81, 6898-6926. [CrossRef]

7. Lang, X.; Zhao, J.; Chen, X. Cooperative photoredox catalysis, Chem. Soc. Rev. 2016, 45, 3026-3038. [CrossRef]

8. Grinberg, V.A.; Medved'Ko, A.V.; Emets, V.V.; Kurzeev, S.A.; Kozyukhin, S.A.; Baranchikov, A.E.; Ivanov, V.K.; Andreev, V.N.; Nizhnikovskii, E.A. Cyclometalated ruthenium complex as a promising sensitizer in dye-sensitized solar cells. Russ. J. Electrochem. 2014, 50, 503-509. [CrossRef]

9. Kreitner, C.; Mengel, A.K.C.; Lee, T.K.; Cho, W.; Char, K.; Kang, Y.S.; Heinze, K. Strongly Coupled Cyclometalated Ruthenium Triarylamine Chromophores as Sensitizers for DSSCs. Chem.-A Eur. J. 2016, 22, 8915-8928. [CrossRef]

10. Wu, W.; Ji, S.; Wu, W.; Guo, H.; Wang, X.; Zhao, J.; Wang, Z. Enhanced luminescence oxygen sensing property of $\mathrm{Ru}(\mathrm{II})$ bispyridine complexes by ligand modification. Sens. Actuators B Chem. 2010, 149, $395-406$. [CrossRef]

11. Zheng, Z.-B.; Duan, Z.-M.; Ma, Y.-Y.; Wang, K.-Z. Highly Sensitive and Selective Difunctional Ruthenium(II) Complex-Based Chemosensor for Dihydrogen Phosphate Anion and Ferrous Cation. Inorg. Chem. 2013, 52, 2306-2316. [CrossRef] [PubMed]

12. Whittemore, T.J.; White, T.A.; Turro, C. New Ligand Design Provides Delocalization and Promotes Strong Absorption throughout the Visible Region in a Ru(II) Complex. J. Am. Chem. Soc. 2018, 140, 229-234. [CrossRef] [PubMed]

13. Archer, S.A.; Raza, A.; Dröge, F.; Robertson, C.C.; Auty, A.J.; Chekulaev, D.M.; Weinstein, J.A.; Keane, T.; Meijer, A.J.H.M.; Haycock, J.W.; et al. A dinuclear ruthenium(ii) phototherapeutic that targets duplex and quadruplex DNA. Chem. Sci. 2019, 10, 3502-3513. [CrossRef] [PubMed]

14. Wagenknecht, P.S.; Ford, P.C. Metal centered ligand field excited states: Their roles in the design and performance of transition metal based photochemical molecular devices. Co-Ord. Chem. Rev. 2011, 255, 591-616. [CrossRef]

15. Arias-Rotondo, D.M.; McCusker, J.K. The photophysics of photoredox catalysis: A roadmap for catalyst design. Chem. Soc. Rev. 2016, 45, 5803-5820. [CrossRef]

16. Torres, J.; Carrión, M.C.; Leal, J.; Castañeda, G.; Manzano, B.R.; Jalón, F.A. Homoleptic ruthenium complexes with N-heterocyclic carbene ligands as photosensitizers in the photocatalytic generation of $\mathrm{H} 2$ from water. J. Organomet. Chem. 2019, 898, 120880. [CrossRef]

17. Kreitner, C.; Heinze, K. Excited state decay of cyclometalated polypyridine ruthenium complexes: Insight from theory and experiment. Dalton Trans. 2016, 45, 13631-13647. [CrossRef]

18. Thompson, D.W.; Ito, A.; Meyer, T.J. $\left[\mathrm{Ru}(\mathrm{bpy})_{3}\right]^{2+*}$ and other remarkable metal-to-ligand charge transfer (MLCT) excited states*. Pure Appl. Chem. 2013, 85, 1257-1305. [CrossRef]

19. Flamigni, L.; Barbieri, A.; Sabatini, C.; Ventura, B.; Barigelletti, F. Photochemistry and Photophysics of Coordination Compounds: Iridium. In Photochemistry and Photophysics of Coordination Compounds II; Springer: Berlin/Heidelberg, Germany, 2007; Volume 281, pp. 143-203. [CrossRef] 
20. Campagna, S.; Puntoriero, F.; Nastasi, F.; Bergamini, G.; Balzani, V. Photochemistry and Photophysics of Coordination Compounds: Ruthenium. Coord. Chem. Rev. 1998, 171, 3-16. [CrossRef]

21. Juris, A.; Balzani, V.; Barigelletti, F.; Campagna, S.; Belser, P.; Von Zelewsky, A. Ru(II) polypyridine complexes: Photophysics, photochemistry, eletrochemistry, and chemiluminescence. Co-Ord. Chem. Rev. 1988, 84, 85-277. [CrossRef]

22. Brown, G.M.; Sutin, N. A Comparison of the Rates of Electron Exchange Reactions of Ammine Complexes of Ruthenium(II) and-(III) with the Predictions of Adiabatic, Outer-Sphere Electron Transfer Models. J. Am. Chem. Soc. 1979, 101, 883-892. [CrossRef]

23. Ghosh, I.; Shaikh, R.S.; König, B. Sensitization-Initiated Electron Transfer for Photoredox Catalysis. Angew. Chem. Int. Ed. 2017, 56, 8544-8549. [CrossRef] [PubMed]

24. Roeser, S.; Bozoglian, F.; Martínez-Belmonte, M.; Benet-Buchholz, J.; Costa, P.F.; Llobet, A. Chemical, Electrochemical, and Photochemical Catalytic Oxidation of Water to Dioxygen with Mononuclear Ruthenium Complexes. ChemSusChem 2011, 4, 197-207. [CrossRef] [PubMed]

25. Wang, C.-S.; Dixneuf, P.H.; Soulé, J.-F. Photoredox Catalysis for Building C-C Bonds from C(sp2)-H Bonds. Chem. Rev. 2018, 118, 7532-7585. [CrossRef]

26. Demas, J.N.; Harris, E.W.; McBride, R.P. Energy transfer from luminescent transition metal complexes to oxygen. J. Am. Chem. Soc. 1977, 99, 3547-3551. [CrossRef]

27. Wrighton, M.; Markham, J. Quenching of the luminescent state of tris(2,2'-bipyridine)ruthenium(II) by electronic energy transfer. J. Phys. Chem. 1973, 77, 3042-3044. [CrossRef]

28. Sutin, N.; Creutz, C. Properties and Reactivities of the Luminescent Excited States of Polypyridine Complexes of Ruthenium(II) and Osmium(II). Photochem. Radiat. Chem. 1978, 168, 1-27. [CrossRef]

29. Tanner, D.D.; Chen, J.J. On the mechanism of the reduction of $\alpha$-halo ketones by 1,3-dimethyl2-phenylbenzimidazoline. Reduction by a SET-hydrogen atom abstraction chain mechanism. J. Org. Chem. 1989, 54, 3842-3846. [CrossRef]

30. Koziakov, D.; Majek, M.; Von Wangelin, A.J. Radical Aromatic Trifluoromethylthiolation: Photoredox Catalysis vs. Base Mediation. Eur. J. Org. Chem. 2017, 2017, 6722-6725. [CrossRef]

31. Koike, T.; Akita, M. Visible-light radical reaction designed by Ru- and Ir-based photoredox catalysis. Inorg. Chem. Front. 2015, 2, 562-576. [CrossRef]

32. Voutyritsa, E.; Triandafillidi, I.; Tzouras, N.V.; Nikitas, N.F.; Pefkianakis, E.K.; Vougioukalakis, G.C.; Kokotos, C.G. Photocatalytic Atom Transfer Radical Addition to Olefins Utilizing Novel Photocatalysts. Molecules 2019, 24, 1644. [CrossRef] [PubMed]

33. Ghosh, I.; Marzo, L.; Das, A.; Shaikh, R.; König, B. Visible Light Mediated Photoredox Catalytic Arylation Reactions. Acc. Chem. Res. 2016, 49, 1566-1577. [CrossRef] [PubMed]

34. Sagadevan, A.; Greaney, M.F. meta-Selective C-H Activation of Arenes at Room Temperature Using Visible Light: Dual-Function Ruthenium Catalysis. Angew. Chem. Int. Ed. 2019, 58, 9826-9830. [CrossRef] [PubMed]

35. Ischay, M.A.; Anzovino, M.E.; Du, J.; Yoon, T.P. Efficient visible light photocatalysis of [2 + 2] enone cycloadditions. J. Am. Chem. Soc. 2008, 130, 12886-12887. [CrossRef] [PubMed]

36. Du, J.; Yoon, T.P. [2 + 2] Cycloadditions by Visible Light Photocatalysis. Synfacts 2009, 2010, 79. [CrossRef]

37. Osawa, M.; Nagai, H.; Akita, M. Photo-activation of Pd-catalyzed Sonogashira coupling using a Ru/bipyridine complex as energy transfer agent. Dalton Trans. 2006, 8, 827-829. [CrossRef] [PubMed]

38. Joe, C.L.; Doyle, A.G. Direct Acylation of C (sp (3))-H Bonds Enabled by Nickel and Photoredox Catalysis. Angew. Chem. Int. Ed. 2016, 55, 4040-4043. [CrossRef]

39. Kalyani, D.; McMurtrey, K.B.; Neufeldt, S.R.; Sanford, M.S. Room-Temperature C-H Arylation: Merger of Pd-Catalyzed C-H Functionalization and Visible-Light Photocatalysis. J. Am. Chem. Soc. 2011, 133, 18566-18569. [CrossRef]

40. Ye, Y.; Sanford, M.S. Merging Visible-Light Photocatalysis and Transition-Metal Catalysis in the Copper-Catalyzed Trifluoromethylation of Boronic Acids with CF3I. J. Am. Chem. Soc. 2012, 134, 9034-9037. [CrossRef]

41. Gao, C.; Wang, J.; Xu, H.; Xiong, Y. Coordination chemistry in the design of heterogeneous photocatalysts. Chem. Soc. Rev. 2017, 46, 2799-2823. [CrossRef]

42. Lowry, M.S.; Bernhard, S. Synthetically Tailored Excited States: Phosphorescent, Cyclometalated Iridium(III) Complexes and Their Applications. Chem.-A Eur. J. 2006, 12, 7970-7977. [CrossRef] [PubMed] 
43. Hammes-Schiffer, S. Catalysts by Design: The Power of Theory. Acc. Chem. Res. 2017, 50, 561-566. [CrossRef] [PubMed]

44. Deaton, J.C.; Castellano, F.N. Archetypal Iridium(III) Compounds for Optoelectronic and Photonic Applications. In Iridium(III) in Optoelectronic and Photonics Applications; WILEY: Hoboken, NJ, USA, 2017; pp. 1-69. [CrossRef]

45. Mede, T.; Jäger, M.; Schubert, U.S. “Chemistry-on-the-complex”: Functional RuII polypyridyl-type sensitizers as divergent building blocks. Chem. Soc. Rev. 2018, 47, 7577-7627. [CrossRef] [PubMed]

46. Sperger, T.; Sanhueza, I.A.; Kalvet, I.; Schoenebeck, F. Computational Studies of Synthetically Relevant Homogeneous Organometallic Catalysis Involving Ni, Pd, Ir, and Rh: An Overview of Commonly Employed DFT Methods and Mechanistic Insights. Chem. Rev. 2015, 115, 9532-9586. [CrossRef]

47. Demissie, T.B.; Ruud, K.; Hansen, J.H. DFT as a Powerful Predictive Tool in Photoredox Catalysis: Redox Potentials and Mechanistic Analysis. Organometallics 2015, 34, 4218-4228. [CrossRef]

48. Munz, D. Pushing Electrons-Which Carbene Ligand for Which Application? Organometallics 2018, 37, 275-289. [CrossRef]

49. Hopkinson, M.N.; Richter, C.; Schedler, M.; Glorius, F. An overview of N-heterocyclic carbenes. Nature 2014, 510, 485-496. [CrossRef]

50. Nesterov, V.; Reiter, D.; Bag, P.; Frisch, P.; Holzner, R.; Porzelt, A.; Inoue, S. NHCs in Main Group Chemistry. Chem. Rev. 2018, 118, 9678-9842. [CrossRef]

51. Vivancos, Á.; Segarra, C.; Albrecht, M. Mesoionic and Related Less Heteroatom-Stabilized N-Heterocyclic Carbene Complexes: Synthesis, Catalysis, and Other Applications. Chem. Rev. 2018, 118, 9493-9586. [CrossRef]

52. Cundari, T.R.; Gordon, M.S. Principal resonance contributors to high-valent, transition-metal alkylidene complexes. J. Am. Chem. Soc. 1991, 113, 5231-5243. [CrossRef]

53. Marion, N.; Navarro, O.; Mei, J.; Stevens, E.D.; Scott, N.M.; Nolan, S.P. Modified (NHC)Pd(allyl)Cl (NHC =N-Heterocyclic Carbene) Complexes for Room-Temperature Suzuki-Miyaura and Buchwald-Hartwig Reactions. J. Am. Chem. Soc. 2006, 128, 4101-4111. [CrossRef] [PubMed]

54. Matteucci, E.; Monti, F.; Mazzoni, R.; Baschieri, A.; Bizzarri, C.; Sambri, L. Click-Derived Triazolylidenes as Chelating Ligands: Achievement of a Neutral and Luminescent Iridium(III)-Triazolide Complex. Inorg. Chem. 2018, 57, 11673-11686. [CrossRef] [PubMed]

55. Sinn, S.; Schulze, B.; Friebe, C.; Brown, D.G.; Jäger, M.; Altuntaş, E.; Kübel, J.; Guntner, O.; Berlinguette, C.P.; Dietzek, B.; et al. Physicochemical Analysis of Ruthenium(II) Sensitizers of 1,2,3-Triazole-Derived Mesoionic Carbene and Cyclometalating Ligands. Inorg. Chem. 2014, 53, 2083-2095. [CrossRef] [PubMed]

56. Schleicher, D.; Leopold, H.; Borrmann, H.; Strassner, T. Ruthenium(II) Bipyridyl Complexes with Cyclometalated NHC Ligands. Inorg. Chem. 2017, 56, 7217-7229. [CrossRef] [PubMed]

57. Soellner, J.; Císařová, I.; Strassner, T. Ruthenium(II) Bipyridyl Complexes with C $\wedge$ C* Cyclometalated Mesoionic Carbene Ligands. Organometallics 2018, 37, 4619-4629. [CrossRef]

58. Benítez, D.; Shapiro, N.D.; Tkatchouk, E.; Wang, Y.; Goddard, W.A.; Toste, F.D. A bonding model for gold(I) carbene complexes. Nat. Chem. 2009, 1, 482-486. [CrossRef]

59. Danopoulos, A.A.; Simler, T.; Braunstein, P. N-Heterocyclic Carbene Complexes of Copper, Nickel, and Cobalt. Chem. Rev. 2019, 119, 3730-3961. [CrossRef]

60. Chábera, P.; Kjaer, K.S.; Prakash, O.; Honarfar, A.; Liu, Y.; Fredin, L.A.; Harlang, T.C.B.; Lidin, S.; Uhlig, J.; Sundström, V.; et al. FeII Hexa N-Heterocyclic Carbene Complex with a 528 ps Metal-to-Ligand Charge-Transfer Excited-State Lifetime. J. Phys. Chem. Lett. 2018, 9, 459-463. [CrossRef]

61. Fredin, L.A.; Pápai, M.I.; Rozsályi, E.; Vankó, G.; Wärnmark, K.; Sundström, V.; Persson, P. Exceptional Excited-State Lifetime of an Iron(II)-N-Heterocyclic Carbene Complex Explained. J. Phys. Chem. Lett. 2014, 5, 2066-2071. [CrossRef]

62. Son, S.U.; Park, K.H.; Lee, Y.-S.; Kim, B.Y.; Choi, C.H.; Lah, M.S.; Jang, Y.H.; Jang, D.-J.; Chung, Y.K. Synthesis of $\mathrm{Ru}(\mathrm{II})$ Complexes of N-Heterocyclic Carbenes and Their Promising Photoluminescence Properties in Water. Inorg. Chem. 2004, 43, 6896-6898. [CrossRef]

63. Schweinfurth, D.; Hettmanczyk, L.; Suntrup, L.; Sarkar, B. Metal Complexes of Click-Derived Triazoles and Mesoionic Carbenes: Electron Transfer, Photochemistry, Magnetic Bistability, and Catalysis. Z. Anorg. Allg. Chem. 2017, 643, 554-584. [CrossRef] 
64. Biner, M.; Buergi, H.B.; Ludi, A.; Roehr, C. Crystal and molecular structures of [Ru(bpy) 3 (PF6)3 and [Ru(bpy) $\left.)_{3}\right](\mathrm{PF} 6) 2$ at 105 K. J. Am. Chem. Soc. 1992, 114, 5197-5203. [CrossRef]

65. Thoresen, E.M.; Balcells, D.; Øien-Ødegaard, S.; Hylland, K.T.; Tilset, M.; Amedjkouh, M. Cyclometalated ruthenium complexes with carboxylated ligands from a combined experimental/computational perspective. Dalton Trans. 2018, 47, 2589-2601. [CrossRef] [PubMed]

66. Barbante, G.J.; Francis, P.S.; Hogan, C.F.; Kheradmand, P.R.; Wilson, D.J.D.; Barnard, P.J. Electrochemiluminescent Ruthenium(II) N-Heterocyclic Carbene Complexes: A Combined Experimental and Theoretical Study. Inorg. Chem. 2013, 52, 7448-7459. [CrossRef]

67. Kepp, K.P. Consistent descriptions of metal-ligand bonds and spin-crossover in inorganic chemistry. Co-Ord. Chem. Rev. 2013, 257, 196-209. [CrossRef]

68. Skara, G.; Gimferrer, M.; De Proft, F.; Salvador, P.; Pinter, B. Scrutinizing the Noninnocence of Quinone Ligands in Ruthenium Complexes: Insights from Structural, Electronic, Energy, and Effective Oxidation State Analyses. Inorg. Chem. 2016, 55, 2185-2199. [CrossRef]

69. Skara, G.; Pinter, B.; Geerlings, P.; De Proft, F. Revealing the thermodynamic driving force for ligand-based reductions in quinoids; conceptual rules for designing redox active and non-innocent ligands. Chem. Sci. 2015, 6, 4109-4117. [CrossRef]

70. Park, H.-J.; Yoo, S.; Shin, I.-S.; Chung, Y.K.; Kim, J. Color-Tunable Electrogenerated Chemiluminescence of RutheniumN-Heterocyclic Carbene Complexes. Electroanalysis 2013, 25, 1111-1115. [CrossRef]

71. Park, H.-J.; Chung, Y.K. Ru(ii) complexes with N-heterocyclic carbene ligands or terpyridine analogues: Synthesis, characterization, and electrochemical and proton-dependent spectrometric properties. Dalton Trans. 2012, 41, 5678. [CrossRef]

72. Löwdin, P.O. On the Non-Orthogonality Problem Connected with the Use of Atomic Wave Functions in the Theory of Molecules and Crystals. J. Chem. Phys. 1950, 18, 365. [CrossRef]

73. Baker, J. Classical chemical concepts from ab initio SCF calculations. Theor. Chem. Acc. 1985, 68, 221-229. [CrossRef]

74. Kar, T.; Sannigrahi, A.; Mukherjee, D. Comparison of atomic charges, valencies and bond orders in some hydrogen-bonded complexes calculated from Mulliken and Löwdin SCF density matrices. J. Mol. Struct. Theochem 1987, 153, 93-101. [CrossRef]

75. Ochola, J.R.; Wolf, M.O. The effect of photocatalyst excited state lifetime on the rate of photoredox catalysis. Org. Biomol. Chem. 2016, 14, 9088-9092. [CrossRef] [PubMed]

76. Dongare, P.; Myron, B.D.B.; Wang, L.; Thompson, D.W.; Meyer, T.J. [Ru(bpy) $]^{2+*}$ revisited. Is it localized or delocalized? How does it decay? Coord. Chem. Rev. 2017, 345, 86-107. [CrossRef]

77. Jäger, M.; Freitag, L.; Gonzalez, L. Using computational chemistry to design Ru photosensitizers with directional charge transfer. Co-Ord. Chem. Rev. 2015, 304-305, 146-165. [CrossRef]

78. Caspar, J.V.; Meyer, T.J. Photochemistry of Ru(bpy) 32+ Solvent Effects. J. Am. Chem. Soc. 1983, 105, 5583-5590. [CrossRef]

79. Sauvage, J.P.; Collin, J.P.; Chambron, J.C.; Guillerez, S.; Coudret, C.; Balzani, V.; Barigelletti, F.; De Cola, L.; Flamigni, L. Ruthenium(II) and Osmium(II) Bis(terpyridine) Complexes in Covalently-Linked Multicomponent Systems: Synthesis, Electrochemical Behavior, Absorption Spectra, and Photochemical and Photophysical Properties. Chem. Rev. 1994, 94, 993-1019. [CrossRef]

80. Kalyanasundaram, K.; Nazeeruddin, K. Tuning of the CT excited state and validity of the energy gap law in mixed ligand complexes of $\mathrm{Ru}(\mathrm{II})$ containing 4,4'-dicarboxy-2,2'-bipyridine. Chem. Phys. Lett. 1992, 193, 292-297. [CrossRef]

81. Caspar, J.V.; Kober, E.M.; Sullivan, B.P.; Meyer, T.J. Application of the energy gap law to the decay of charge-transfer excited states. J. Am. Chem. Soc. 1982, 104, 630-632. [CrossRef]

82. Yoshikawa, N.; Yamabe, S.; Sakaki, S.; Kanehisa, N.; Inoue, T.; Takashima, H. Transition states of the 3MLCT to $3 \mathrm{MC}$ conversion in $\mathrm{Ru}(\mathrm{bpy})_{2}$ (phen derivative) $^{2+}$ complexes. J. Mol. Struct. 2015, 1094, 98-108. [CrossRef]

83. Österman, T.; Abrahamsson, M.; Becker, H.-C.; Hammarström, L.; Persson, P. Influence of Triplet State Multidimensionality on Excited State Lifetimes of Bis-tridentate RuII Complexes: A Computational Study. J. Phys. Chem. A 2012, 116, 1041-1050. [CrossRef] [PubMed]

84. Österman, T.; Persson, P. Excited state potential energy surfaces of bistridentate Ru II complexes-A. TD-DFT study. Chem. Phys. 2012, 407, 76-82. [CrossRef] 
85. Johnson, E.R.; Keinan, S.; Mori-Sánchez, P.; Contreras-García, J.; Cohen, A.J.; Yang, W. Revealing noncovalent interactions. J. Am. Chem. Soc. 2010, 132, 6498-6506. [CrossRef] [PubMed]

86. Wu, P.; Chaudret, R.; Hu, X.; Yang, W. Noncovalent Interaction Analysis in Fluctuating Environments. J. Chem. Theory Comput. 2013, 9, 2226-2234. [CrossRef] [PubMed]

87. Contreras-García, J.; Yang, W.; Johnson, E.R. Analysis of Hydrogen-Bond Interaction Potentials from the Electron Density: Integration of Noncovalent Interaction Regions. J. Phys. Chem. A 2011, 115, 12983-12990. [CrossRef] [PubMed]

88. Contreras-García, J.; Johnson, E.R.; Keinan, S.; Chaudret, R.; Piquemal, J.-P.; Beratan, D.N.; Yang, W. NCIPLOT: A Program for Plotting Noncovalent Interaction Regions. J. Chem. Theory Comput. 2011, 7, 625-632.

89. Neese, F. The ORCA program system, Wiley Interdiscip. Rev. Comput. Mol. Sci. 2012, 2, 73-78. [CrossRef]

90. Perdew, J.P.; Burke, K.; Ernzerhof, M. Generalized Gradient Approximation Made Simple. Phys. Rev. Lett. 1996, 77, 3865-3868. [CrossRef]

91. Perdew, J.P.; Ernzerhof, M.; Burke, K. Generalized Gradient Approximation Made Simple. [Phys. Rev. Lett. 1996, 77, 3865-3868.] [ERRATUM]. Phys. Rev. Lett. 1997, 78, 1396. [CrossRef]

92. Weigend, F.; Ahlrichs, R. Balanced basis sets of split valence, triple zeta valence and quadruple zeta valence quality for H to Rn: Design and assessment of accuracy. Phys. Chem. Chem. Phys. 2005, 7, 3297. [CrossRef]

93. Andrae, D.; Dolg, M.; Stoll, H.; Häußermann, U.; Preuß, H. Energy-adjustedab initio pseudopotentials for the second and third row transition elements. Theor. Chem. Acc. 1990, 77, 123-141. [CrossRef]

94. Eichkorn, K.; Treutler, O.; Öhm, H.; Häser, M.; Ahlrichs, R. Auxiliary basis sets to approximate Coulomb potentials. Chem. Phys. Lett. 1995, 240, 283-290. [CrossRef]

95. Grimme, S.; Ehrlich, S.; Goerigk, L. Effect of the damping function in dispersion corrected density functional theory. J. Comput. Chem. 2011, 32, 1456-1465. [CrossRef] [PubMed]

96. Marenich, A.V.; Cramer, C.J.; Truhlar, D.G. Universal Solvation Model Based on Solute Electron Density and on a Continuum Model of the Solvent Defined by the Bulk Dielectric Constant and Atomic Surface Tensions. J. Phys. Chem. B 2009, 113, 6378-6396. [CrossRef]

97. Roy, L.E.; Jakubikova, E.; Guthrie, M.G.; Batista, E.R. Calculation of One-Electron Redox Potentials Revisited. Is It Possible to Calculate Accurate Potentials with Density Functional Methods? J. Phys. Chem. A 2009, 113, 6745-6750. [CrossRef]

98. Baik, M.-H.; Friesner, R.A. Computing Redox Potentials in Solution: Density Functional Theory as A Tool for Rational Design of Redox Agents. J. Phys. Chem. A 2002, 106, 7407-7412. [CrossRef]

99. Li, J.; Fisher, C.L.; Chen, J.L.; Bashford, N.; Noodleman, L. Calculation of Redox Potentials and pKaValues of Hydrated Transition Metal Cations by a Combined Density Functional and Continuum Dielectric Theory. Inorg. Chem. 1996, 35, 4694-4702. [CrossRef]

100. Lu, T.; Chen, F. Multiwfn: A multifunctional wavefunction analyzer. J. Comput. Chem. 2012, 33, 580-592. [CrossRef]

101. Humphrey, W.; Dalke, A.; Schulten, K. VMD: Visual Molecular Dynamics. J. Mol Graph. 1996, 14, $33-38$. [CrossRef]

(C) 2020 by the authors. Licensee MDPI, Basel, Switzerland. This article is an open access article distributed under the terms and conditions of the Creative Commons Attribution (CC BY) license (http://creativecommons.org/licenses/by/4.0/). 